\title{
The Transforming Mobility Ecosystem: Enabling an Energy-Efficient Future
}

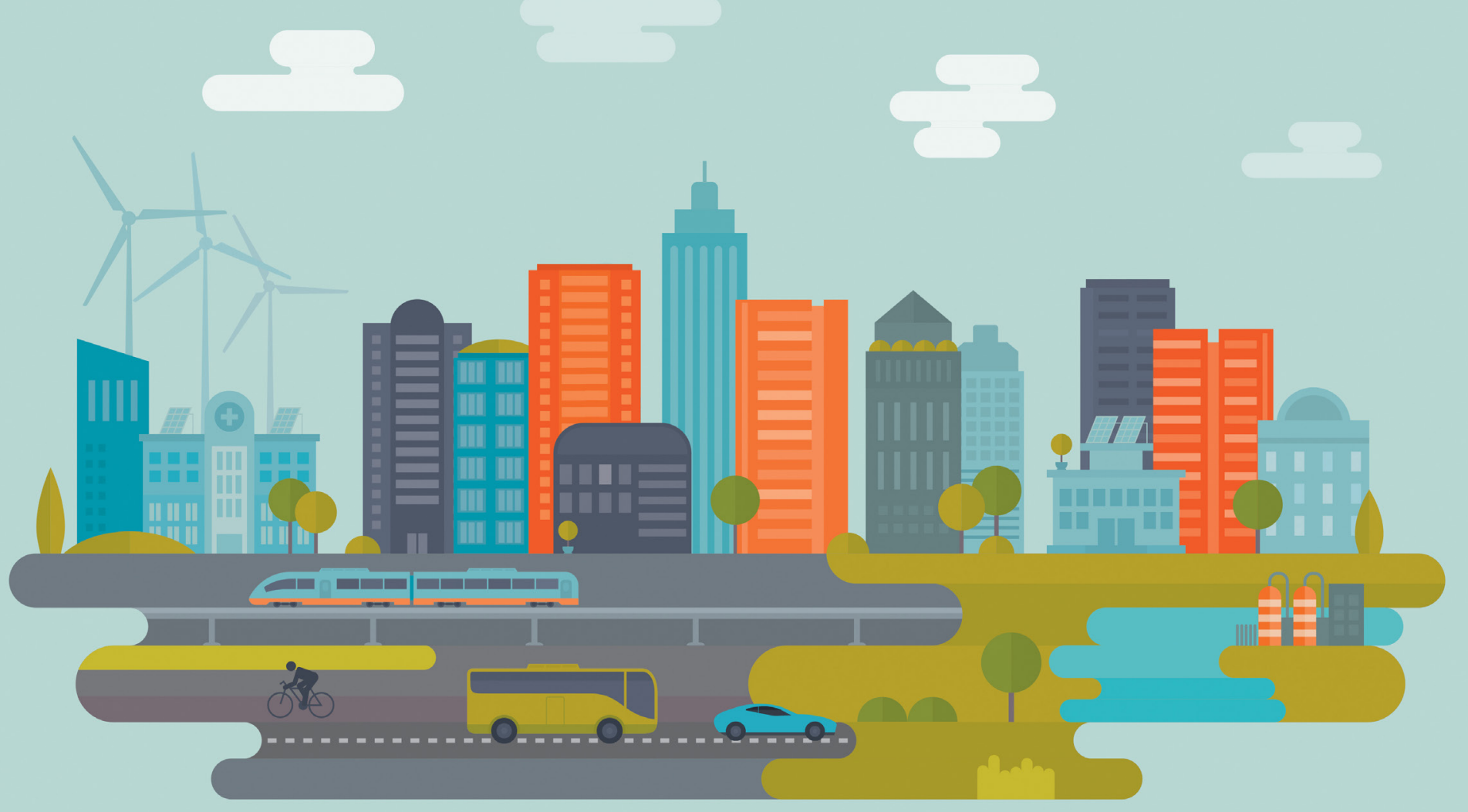

U.S. DEPARTMENT OF

ENERGY

Energy Efficiency \& Renewable Energy 

This report is being disseminated by the Department of Energy (DOE). As such, the document was prepared in compliance with Section 515 of the Treasury and General Government Appropriations Act for Fiscal Year 2001 (Public Law 106-554) and information quality guidelines issued by DOE. Though this report does not constitute "influential" information, as that term is defined in DOE's information quality guidelines or the Office of Management and Budget's Information Quality Bulletin for Peer Review, as detailed in Acknowledgment, the report was reviewed both internally and externally prior to publication.

\section{NOTICE}

This report was prepared as an account of work sponsored by an agency of the US government. Neither the US government nor any agency thereof, nor any of their employees, makes any warranty, express or implied, or assumes any legal liability or responsibility for the accuracy, completeness, or usefulness of any information, apparatus, product, or process disclosed, or represents that its use would not infringe privately owned rights. Reference herein to any specific commercial product, process, or service by trade name, trademark, manufacturer, or otherwise does not necessarily constitute or imply its endorsement, recommendation, or favoring by the US government or any agency thereof. The views and opinions of authors expressed herein do not necessarily state or reflect those of the US government or any agency thereof.

Available electronically at https://energy.gov/eere/vehicles/downloads/ transforming-mobility-ecosystem-report. 


\section{Table of contents}

Message from the Deputy Assistant Secretary for Sustainable Transportation III

Key Terms and Acronyms IV

Foreword $\quad \mathrm{V}$

Introduction 1

Introduction to Mobility Narratives 6

- Incremental Change 7

- Personal-Automated 7

- Shared-Mobility 7

- Shared-Automated 8

Mobility Futures-Energy Implications 10

- Personal-Automated 10

- Shared-Mobility 14

- Shared-Automated 17

Ripple Effects

- The Perfect Storm-Nexus of Low Cost Personal and Goods Mobility 21

- Letting Go of the Wheel-No More 'Pedal to the Metal' 21

- The Invincible Pod That Could-Life of a Battery 22

- Supply Chain Disorientation-Streamline for Success 22

- US Manufacturing Footprint-Strengthening Competitiveness in Mobility Futures 23

- Shared-Automated Prolongs Dominance of ICEs-Transitioning to a ZEV Future 23

- Avoiding Revenue Drought-Paying for a New Mobility Paradigm 24

- Job Dislocation - Direct and Indirect Impacts 24

Conclusion 26

Acknowledgements 28

References 29 


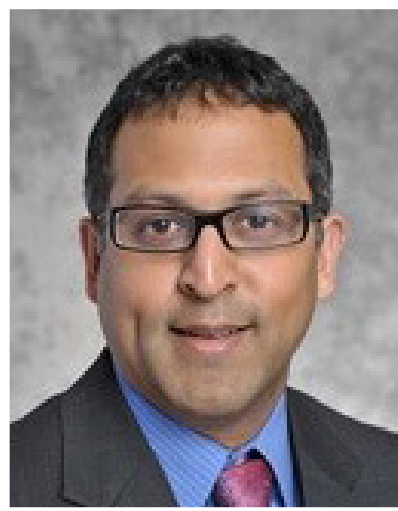

Over the next decade, the transportation sector is poised for rapid change, propelled toward a new mobility future carried by strong technology currents and the confluence of prevailing megatrends that are giving rise to a massive wave of transformation. These major forces hold the promise of shaping a new mobility future-one that unlocks tremendous economic value, provides unprecedented gains in safety, offers affordable and equal accessibility, and enables the transition to energy-efficient transport of people and goods.

They come, however, with cautionary viewpoints on energy consumption of the entire sector, as well as potential ripple effects across the broader economy, including competitiveness and jobs, which necessitate the need to carefully guide the emergent future.

The transportation sector currently accounts for 27 percent of total US energy consumption, and global imperatives are driving increases in energy efficiency. Inefficient use of energy could lead to higher or volatile transportation costs, less discretionary income for families, and a less competitive economy. From the Energy Department's perspective, it is essential that we hit our stride now with the adoption of energy-efficient technologies, given the multi-decadal time frame required to overhaul our nation's fleets.

The primary goal of this paper is to bring a much-needed focus to the range of possible impacts this transformation may have on energy, while acknowledging the economic, safety, and accessibility implications. In addition, this paper highlights the impacts that the mobility system of the future will have on our built environment, and how these interactions could change our cityscapes, as well as suburban and rural areas.

I would like to express my sincerest thanks to the many individuals from across government agencies, industry, academia, and our national labs for lending their insights, support, and feedback in the creation of this paper. It will set the stage for future dialogue as we navigate our way toward that most aspiring future of economic value creation, unprecedented safety, affordable accessibility for all, and energy-efficient mobility.

Sincerely,

\section{Reuben Sarkar}

Reuben Sarkar

Deputy Assistant Secretary for Sustainable Transportation

Office of Energy Efficiency and Renewable Energy

US Department of Energy 


\section{Key Terms and Acronyms}

\begin{tabular}{|c|c|}
\hline 4G & Fourth Generation of Mobile Telecommunications \\
\hline $5 \mathrm{G}$ & Fifth Generation of Mobile Telecommunications \\
\hline Automated Vehicle & $\begin{array}{l}\text { Self-driving, and full automated defined as Level } 4 \text { or } 5 \text { functionality by SAE } \\
\text { International }\end{array}$ \\
\hline DOE & Department of Energy \\
\hline Eco-Driving & Driving style or features that improve fuel efficiency and reduce emissions \\
\hline EERE & Energy Efficiency and Renewable Energy \\
\hline EIA & Energy Information Administration \\
\hline GHG & Greenhouse gas \\
\hline ICEs & Internal Combustion Engines \\
\hline Mobility On-Demand & $\begin{array}{l}\text { Ridesourcing/Transportation Network Companies (TNC) (e.g., Lyft, Uber); ride } \\
\text { splitting (e.g., Lyft Line, UberPOOL); ride-hailing or app-enabled taxi services } \\
\text { (e.g., Curb, Flywheel); microtransit (e.g., Bridj); Courier Network Services (CNS) }\end{array}$ \\
\hline Platooning & $\begin{array}{l}\text { Vehicles driving in tandem enabled by connected and automated technology } \\
\text { features, such as radar, vehicle to vehicle communications that allow for safely } \\
\text { reducing separation between traveling vehicles in order to reduce drag and } \\
\text { improve fuel economy and time traveled }\end{array}$ \\
\hline Ridesharing & Carpooling (e.g., Scoop, Waze) and vanpooling \\
\hline Right Sizing & $\begin{array}{l}\text { Matching the size of the vehicle to the application or type of use (e.g., tailored to } \\
\text { passenger occupancy) }\end{array}$ \\
\hline Shared Mobility & $\begin{array}{l}\text { Mobility On-Demand (ridesourcing, ride splitting, ride-hailing or app-enabled taxi } \\
\text { services, microtransit, courier network services), Ridesharing, Carsharing (e.g., } \\
\text { Zipcar, Car2Go), Bikesharing }\end{array}$ \\
\hline V2X & $\begin{array}{l}\text { Vehicle to External environment connectivity, including Vehicle to Vehicle (V2V), } \\
\text { Vehicle to Infrastructure (V2I), Vehicle to Grid (V2G) }\end{array}$ \\
\hline VMT & Vehicle miles traveled \\
\hline ZEVs & $\begin{array}{l}\text { Zero Emission Vehicles; Vehicle that emits no tailpipe pollutants; includes Battery } \\
\text { Electric Vehicles (BEVs) and Fuel-Cell Electric Vehicles (FCEVs) }\end{array}$ \\
\hline Zero-Occupancy Vehicles & Driverless vehicles carrying no passengers \\
\hline
\end{tabular}




\section{Foreword}

The intent of this paper is to provide the Energy Department's forethought, along with public and private stakeholder input, on the future of mobility and subsequent impacts on energy consumption and the broader economy.

It introduces four possible mobility futures, or narratives, defined by two factors chosen for their transformative potential and pertinence to the discussion: vehicle control (from driver-only, to fully-automated (self-driving) defined as Level 4 or 5 functionality by SAE International'), and vehicle ownership (from personal ownership to fully shared vehicles²).

These narratives are further framed by contrasting aspirational and cautionary energy outcomes, which are used to derive a series of observations and insights on market, technology, and policy factors to reduce energy consumption, or elicit pathways to decouple energy from carbon.

As with most transformative change, there will likely be winners and losers within the new economy and a potential redistribution of value across stakeholders. This paper acknowledges that transformation within the transportation sector could entail a broader economy-wide impact (e.g., jobs) with the transference of revenue streams as traditional business models and industries see increased competition from new business models and market players.

This paper, however, does not offer policy recommendations, or provide strategies that would enable one future narrative over the other. Additionally, it does not set target expectations for energy-efficient technologies (e.g., battery costs), but rather observes a range of factors that, ultimately, could shape each future narrative and determine the impacts on energy. It is also recognizes that other factors may emerge in the future that could have a significant energy impact.

It is focused primarily on the light-duty vehicle fleet and the mobility of people. Additional thinking, however, is required to anticipate the full range of energy impacts on the entire mobility system, including other areas of the vehicle fleet (e.g., heavy-duty trucks), other transportation modes (e.g., public transit, aviation), and the movement of goods.

\footnotetext{
'Fully automated is intended to denote Level 4 or 5 functionality, according to SAE International and recently adopted by the US Department of Transportation's "Federal Automated Vehicles Policy" (2016)

${ }^{2}$ Fully shared means that private car ownership either does not exist, or represents such a small share of the vehicle fleet as to be considered negligible. This definition includes a range of on-demand mobility and shared ride services.
} 



\section{Introduction}

A wave of transformation is underway within the transportation sector with more innovation expected in the next decade than in the previous century. Traditional market players and business models are facing increased competition from new entrants seeking to capitalize on advancements in technology and changing consumer preferences. This transition presents a significant opportunity to improve economic productivity and provide unprecedented gains in safety, affordability, and accessibility to the American people.

There will be pros and cons, however, within whichever futures may emerge, including challenges that could inhibit capturing the full suite of benefits or create additional ripple effects (e.g., job dislocation, redistribution of economic value stemming from automation). Additionally, the prevailing models

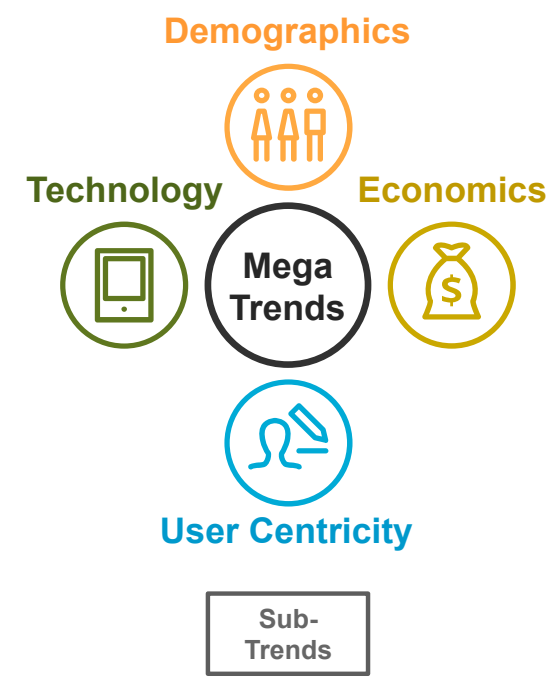

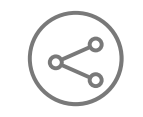

Shared Economy

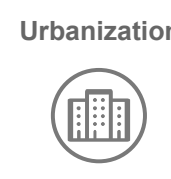

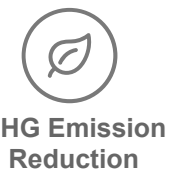

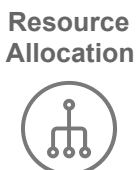

Figure 1. Major forces are shaping the transportation system transportation modes, technologies, and solutions may vary significantly across the country based on the needs and resources of a particular region or community, for example the ways connected, automated and shared vehicles are integrated in rural areas may differ substantially with how they are integrated into urban areas. So, it is likely that various paradigms will co-exist. Ultimately, there will be winners and losers in this new economy as a changing competitive landscape shifts sources of profits towards those most adept to deliver the most value to consumers.

From the Energy Department's perspective, it is critical to better understand how this transformation will impact energy consumption, as well as the broader economy (e.g., jobs, security, manufacturing, competiveness). Additionally, these changes could have profound impacts on future vehicle design and required performance, as well as the built environment, including the design of urban, suburban, and rural areas.

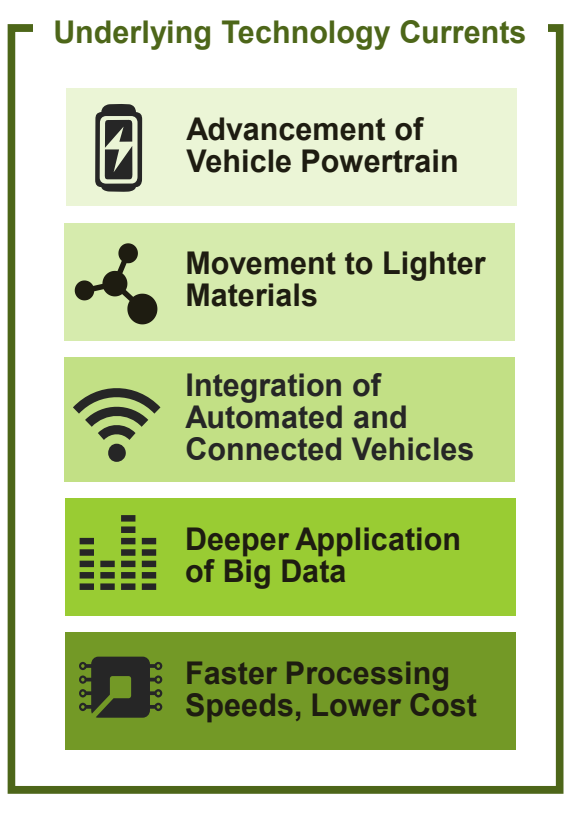


The trajectory of these transformations to the system will be guided by varied market, technology, and policy factors. Currently, the transportation sector accounts for 27 percent of total US energy consumption. Concurrently, global imperatives are pursuing dramatic increases in energy-efficiency and reductions in greenhouse gas (GHG) emissions of greater than $80 \%$ across all sectors by 2050 . Therefore, a concentrated effort to expand the availability of energy-efficient, low-carbon technologies at scale is needed in the near future, given the multi-decadal time frame required to change over our nation's fleets.

Over the last decade, significant breakthroughs have emerged in vehicle and information and communication technology that could enable an energy-efficient future, including advancements in vehicle powertrains, movement to lightweight materials, integration of connected and automated vehicles, deeper applications of big data, and faster, cheaper processing speeds.

At the same time, these underpinning technologies are intersecting with key megatrends, such as changing economics (e.g., increasing global energy demand; shifting population centers to mega-regions and cities), heightened user centricity (e.g., ubiquitous use of smart devices; people-focused business strategies), shifting demographics (e.g., growing and hyper-connective global population), and accelerated adoption of new technologies (e.g., shifting demands from new tech-savvy generations). ${ }^{3}$

At the intersection of these trends are other critical factors shaping mobility. These include the rise of the "shared economy", increased urbanization, increased societal and economic pressure to reduce global GHG emissions, and a rising strain on resource allocation to respond to a growing population.

Additionally, the emergence of new business models for providing shared mobility services, such as ridesourcing or "transportation network companies" (e.g., Lyft, Uber), ridesplitting (e.g., UberPOOL, Lyft Line), ridesharing (e.g., carpooling (Scoop, Waze) and vanpooling), carsharing (e.g., Zipcar, Car2Go), eHail taxi services (e.g., Curb, Flywheel), microtransit (e.g., Bridj), courier network services (CNS), and bikesharing, are rapidly redefining consumer and business options and fundamentally changing the way people move.

The confluence of these forces and new market entrants are shaking up the traditional bounds of the mobility sector and prompting more questions about the impacts on energy. Historically, the Energy Department's Office of Energy Efficiency and Renewable Energy (EERE) has focused on improving efficiencies at the vehicle level and developing alternative fuels. However, the expanding scope and expected transformative disruption in the sector has prompted a realignment of resources to encompass the broader integrated mobility system.

In 2016, EERE launched a new program, Energy Efficient Mobility Systems ${ }^{4}$, which will conduct research, development, and demonstration projects at the nexus of energy and future mobility of people and goods, and identify efficiency gains that could be leveraged from better utilization of the entire system.

But what does the future of mobility look like? What are the ranges of possible scenarios for how people and goods will move in the future? How will these impact future R\&D portfolios? What impact will this change have on energy consumption?

This paper provides insight and observations into future mobility scenarios, with respect to our lightduty fleet, in order to understand the impact on energy consumption of the system. Throughout this paper, energy mix of the future system is assumed to maintain the status quo of today's petroleum-based transportation system. Therefore, any reduction in energy consumption will result in equivalent benefits of reducing $\mathrm{GHG}$ emissions.

It also acknowledges the opportunity to increase carbon efficiency by fuel switching, which could also bring about significant benefits. However, limitless growth in consumption - even if decoupled from emissions - could still create challenges elsewhere

${ }^{3}$ US Department of Transportation. 2015. Beyond Traffic 2045: Trends and Choices. Washington, DC; and Lancefield, David. 2016. PwC Issues: Megatrends; and Schreiber, Uschi. 2015. Megatrends 2015: making sense of a world in motion. EYGM Limited.

${ }^{4}$ Formerly Transportation-as-a-System (Taas). 
in the system (e.g., investment strains on electricity generation capacity and transmission infrastructure).

The ability to set the nation on an energy-efficient trajectory by 2050 will be determined by decisions and investments that must start within the next decade. Given current turnover time for fleets, technologies capable of achieving greater energy-efficiency, as well greater than $80 \%$ reduction in GHG emissions, will need to enter the market and be scaled to full deployment in the very near future (2018-2034). The application of these technologies, and the speed and scale at which they are adopted into the market, however, will be affected by changes to the mobility system.

From an aspirational viewpoint, can the innovations in technology and business models be harnessed for widespread societal benefit, delivering the returns many advances promise such as increased safety, accessibility, reliability, and affordability, while at the same time reducing energy consumption in the transportation system for an energy-efficient mobility future?

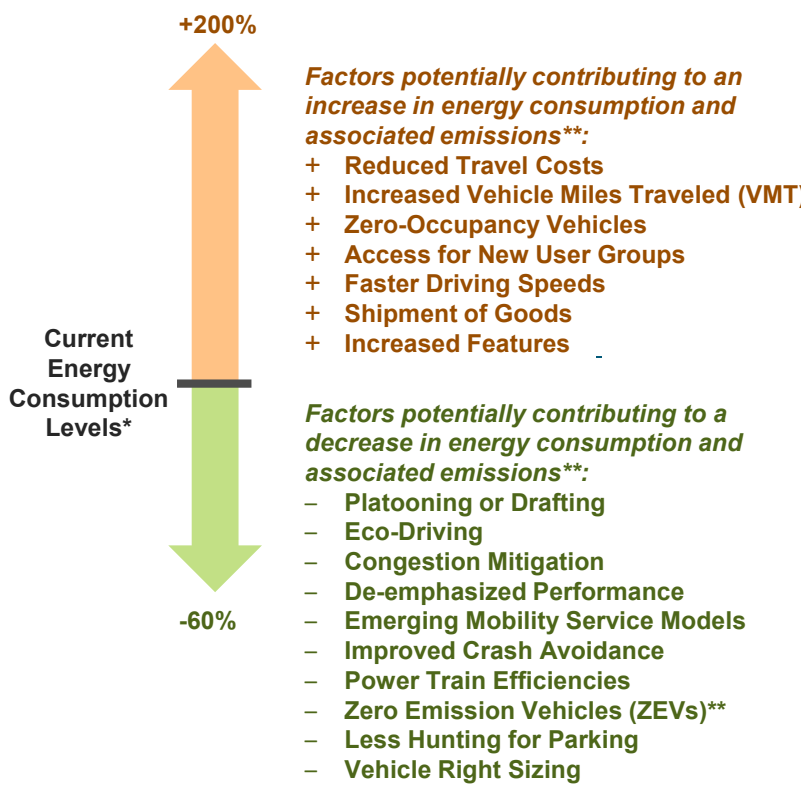

And from a cautionary viewpoint, will inefficient allocation of resources for low-cost mobility services (e.g., inefficient modal shifting), heightened emphasis on vehicle performance, increased vehicle miles traveled (VMT), or dependence on petroleum lead to much higher energy consumption? Will some promises be delivered, such as safety, accessibly, reliability, and affordability, while other potential benefits, specifically energy, are not achieved?

A recent study from the Energy Department National Laboratories suggests a broad range of energy impacts from automated and connected vehicles. This study found that the impact on energy could range from a possible $60 \%$ system-wide decrease in energy consumption to a $200 \%$ system-wide increase energy consumption. $^{5}$ Fuel switching as well as unknown factors about how people will choose to move in the future, however, could expand the range of energy outcomes even further in either direction.

This wide range of possible energy outcomes not only presents an opportunity to drive even more efficient technologies into the market, but also identifies challenges that if not properly managed, could enable increased energy consumption and a less energy efficient system.

Unlocking an energy-efficient mobility ecosystem will require a balance of the market, technological, and policy forces to promote all of the positive societal benefits, but avoid the forces that increase energy consumption. In order to focus a dialogue toward considering these questions and posit the range of energy impacts, EERE developed-with internal and external input- four narratives contextualizing potential energy opportunities and concerns for mobility futures in 2050.

Figure 2. Energy Impacts of Connectivity and Automation

*For assumptions and methodology, see Stephens T. ed al (2016). "Estimated Bounds and Important Factors for Fuel Use and Consumer Costs of Connected and Automated Vehicles." National Renewable Energy Lab. November.

**Zero Emission Vehicles (ZEVs) not accounted in research; fuel switching could increase efficiency gains

${ }^{5}$ Study assumes continued use of internal combustion engines with no fuel or powertrain switching other than potential downsizing of conventional powertrains. For full set of assumptions and methodology, see Stephens T. ed al (2016). Estimated Bounds and Important Factors for Fuel Use and Consumer Costs of Connected and Automated Vehicles." National Renewable Energy Lab. November. 
In the next section, this report will describe these four possible futures that are differentiated by the particular type of model that predominates: Incremental-Change, Personal-Automated, Shared-Mobility, or Shared-Automated. In the following section, we will explore in added depth the positive and negative implications for energy - and broader economy-wide impacts - within each narrative.

Each narrative will observe important questions that frame the examination, including:

- What are the direct and rebound energy impacts of automated vehicles and shared mobility services? How will the density of a geographic area (urban, suburban, or rural) determine the application of these technologies and mobility concepts, and what will be the correlating energy impact?

- What possible scenarios favor advancements in technology and systems that promote efficiency, and what impacts can we anticipate from innovations in vehicle design, materials, and connectivity?

- How will new shared mobility business models, or the adoption of automated vehicles, affect the overall size and utilization rate of the vehicle fleet, and what are the potential impacts on manufacturers and vehicle design?

- What combination of automation, shared mobility services, and other multimodal transportation options will customers favor in the future, and can we better understand the factors that inform their future mobility decisions?

The potential energy impacts within any mobility future-ranging from technologies within the vehicle, to systems level gains across an entire fleet of vehicles to broader societal influences-will be considered against an established set of important indicators, which include but are not limited to those in Figure 3.

In the final section, this report will discuss the indirect non-energy impacts-or ripple effects-that could result from a major transformation in the transportation sector. The basic themes and the contrasting energy impacts of future narratives, as well as indirect non-energy impacts, will be used to establish a foundation to guide collaborations with industry, universities, federal agencies, and other stakeholders in order to accelerate technological innovation and to guide the clearest path toward aspirational energy outcomes and avoid cautionary energy outcomes.

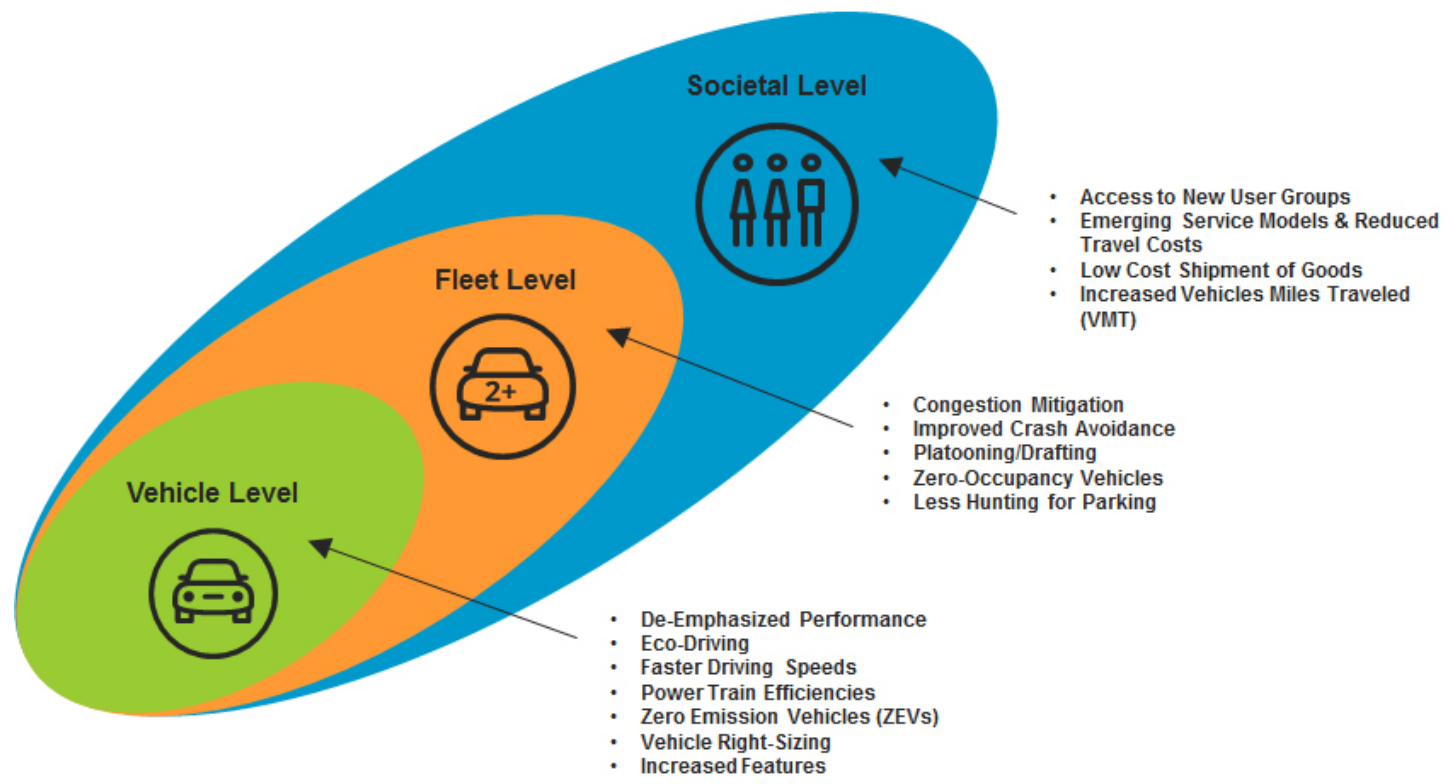

Figure 3. Possible Impacts on Energy at the Vehicle, Fleet/Systems, and Systems-of-Systems Level 


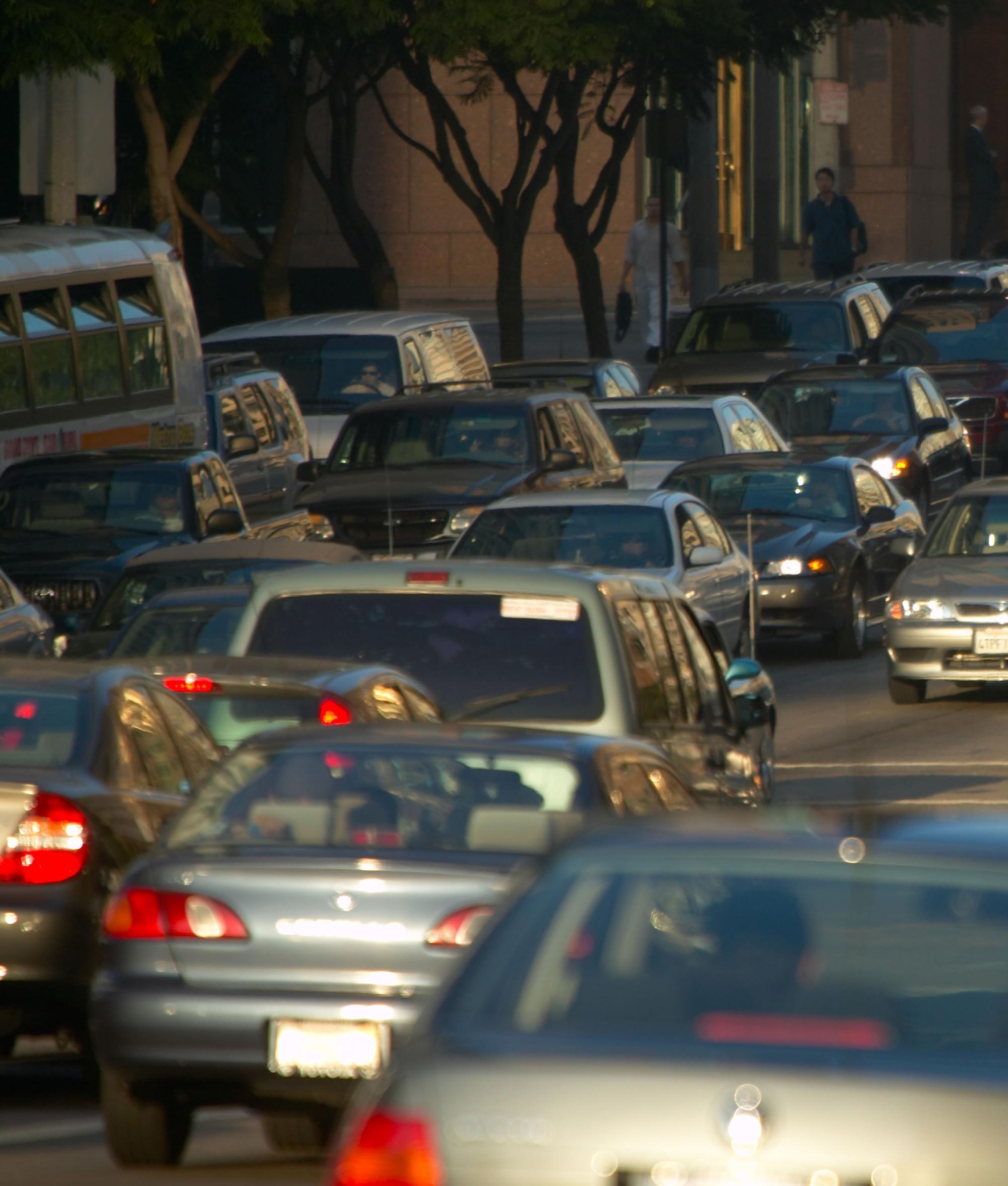




\section{Introduction to Mobility Futures Narratives}

In the future, it is conceivable that a radically different system will have emerged, or alternatively, perhaps very little will have changed. To contextualize the hypothetical and ground the conversation with identifiable markers, this report identifies four potential futures that can be envisioned when viewing through a dual lens of vehicle ownership and vehicle control.

These futures, depicted in Figure 4, form the basis for the following narratives, and are used throughout the report to describe market, technology, and policy factors that shape each mobility future and determine the energy impact. This framework was developed in consultation with stakeholders from industry and the automotive research community, and reflects their views on the varying degrees to which vehicle ownership and vehicle control could drive the most significant disruption.
These narratives should be recognized as tools meant to facilitate derivation of observations and insights about possible mobility futures, rather than forecasts or projections of the future. In reality, future mobility trajectories may include facets of each of the future narratives described. Any of these futures may occur simultaneously, with different consumers and companies requiring diverse transportation modes, leading to the concurrent existence of the future states. Furthermore, consumers could move between these future states based on their specific travel needs at the time.

For this reason, industry leaders and policy makers will need to understand the potential implications of each future state, which include distinct sets of consumer requirements and potential energy impacts.

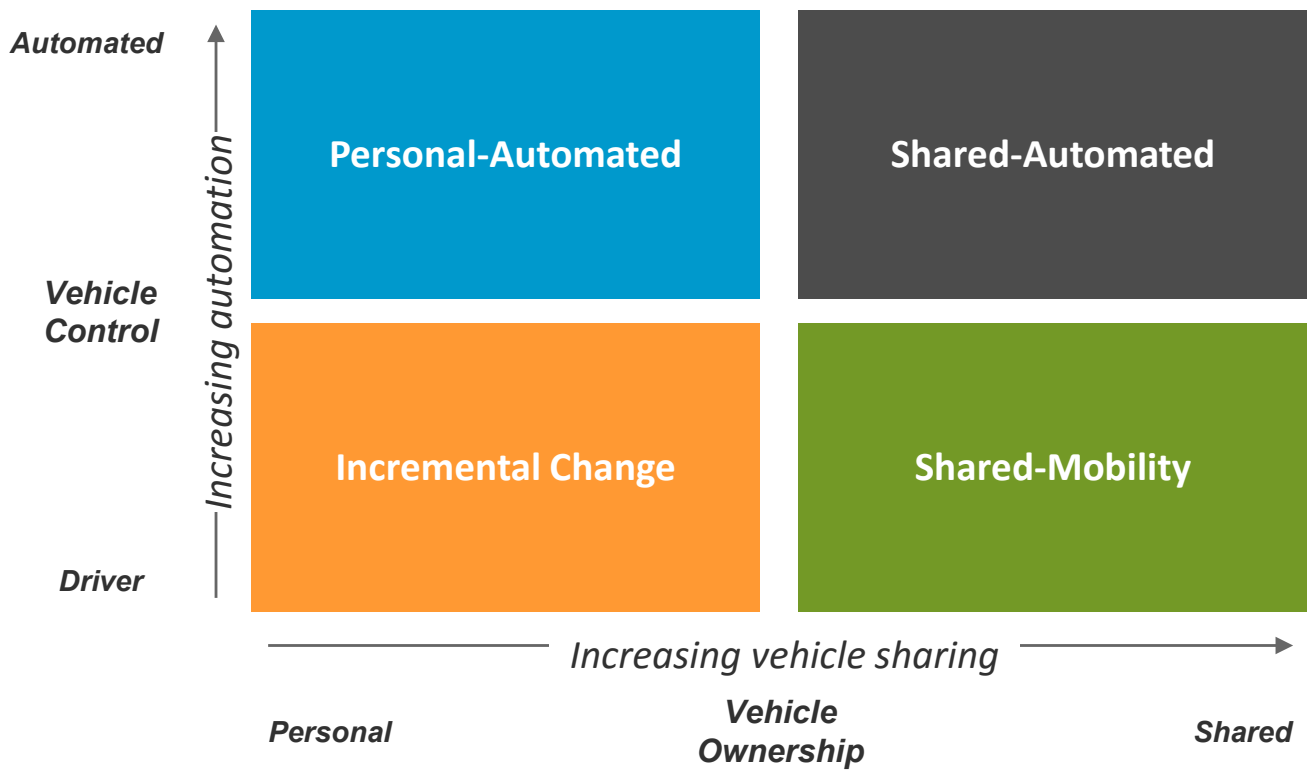

Figure 4. Future state narratives framework ${ }^{6}$

${ }^{6}$ The concept of framing the mobility futures within a two-by-two matrix was raised and discussed in stakeholder meetings with DOE. The matrix depicted in Figure 4 is adapted from: Corwin, Scott, Joe Vitale, Eamonn Kelly, and Elizabeth Cathles. 2015. The future of mobility: How transportation technology and social trends are creating a new business ecosystem. Deloitte University Press. 
In the first future state, Incremental Change anticipates limited transformation beyond the current system, in which personal vehicle ownership prevails and drivers continue to control vehicles. This future persists due to the continued predominance of legacy systems, ranging from transportation assets to manufacturers, the liquid fuel industry, and the large public and private infrastructures that have been constructed over the last century to support the current mobility paradigm.

This future represents a baseline scenario where incremental improvements in efficiency are driven by regulatory mandates and existing research and development with limited breakthroughs. It assumes the majority of asset owners will neither willingly abandon nor eagerly transfer capital into new enterprises, particularly those with uncertain returns. Personal vehicle ownership remains the norm, with consumers continuing to have the privacy, flexibility, security, and convenience that come with vehicle ownership. While driver-assist technologies are available, this future vision assumes that fully automated vehicles would not significantly penetrate the market

With the personal vehicle ownership model dominating, this future state reinforces automakers' reliance on a business model that emphasizes unit sales. They continue to invest in the development and introduction of advanced technologies that enhance the customer experience; other industry players are similarly incented to rely on the practices and structures that have been well established for decades. The urban landscape and current land use patterns (e.g., parking requirements) remain intact. This future exhibits little changes and strong similarities to today's experiences.
The second future state, Personal-Automated, anticipates that automated technology is ubiquitous within all vehicles, and the personal vehicle ownership model prevails. In this future state, drivers prefer owning their own vehicles, and individuals seek automated functionality for its safety and other potential benefits. They continue to own cars for many of the same reasons that they did before the advent of automated vehicles (e.g., convenience, privacy, flexibility). Consumers might even invest more in their vehicles as a new era of customization dawnsthis new segment of the market may offer lighter, higher performance, more technically advanced vehicles that embrace design principles contrapuntal to today's four-door, driver-in-front-on-left, grippingthe-steering-wheel reality.

Moreover, these technologies could promote new commuting realities-one that engenders the pull of suburban sprawl by significantly improving the commuting experience or less efficient land-use patterns. This future presents an opportunity for new market players and partnerships to bring advanced automated and digital technologies to market.

The third future state, Shared-Mobility, anticipates universal access to shared mobility vehicles and rides, whether mobility on-demand, ridesharing, carsharing or bikesharing. In this state, automation remains limited to lower levels (e.g., Levels 1-3, SAE International ${ }^{7}$ ). Multiple vehicle ownership models (e.g., individual leasing or ownership; fleet operator) exist in this future, but sharing is inherently built into the fabric of society and all assets are shared. In this state, growth in the number of service providers and increased competition drive the expansion of

7"Lower levels of connectivity and automation" is intended to denote Levels 1-3, but not Level 4 or 5 functionality, according to SAE International and adopted by the US Department of Transportation's "Federal Automated Vehicles Policy" (2016). 
on-demand mobility and shared ride services into new geographic territories and more diverse customer segments, and consumers more heavily value the convenience of point-to-point transportation. This mitigates the hassle of navigating traffic, or finding parking spaces.

The system significantly expands access to mobility options for non-drivers and the underserved, such as seniors, the disabled, and minors without licenses, as costs drop. In this future state, travel costs per mile decrease, leading many consumers to value share ride services as a more economical and convenient transportation option than personal ownership. However, the price floor is buoyed by the inherent expense of a driver, and could remain cost prohibitive for some communities.

As shared mobility services provide larger shares of local transportation needs, families may reduce the number of cars they own, while others may abandon ownership altogether. The types of

Ultimately, all of these futures are likely to coexist in some form, and consumers will often navigate between them fluidly. Given the unique characteristics of each, a range of energy outcomes is possible, especially within each future. The next section will explore in greater detail how market, policy, and technology factors will influence each future state, with the pros and cons in terms of energy and broader economic impacts. modal shifting and number of passengers per vehicle, however, could be determined by changes in behavior and interactions with the mobility system. Limited connectivity and access to smart system routing makes travel somewhat more efficient, but the continued presence of a driver limits the efficiency potential afforded by fully connected and automated operation. In addition, an evolution toward this future will be less innovative or unlikely to spark radical vehicle redesign.

The fourth future state, Shared-Automated, anticipates a convergence of automated vehicles and shared mobility service trends. In this future, mobility management companies offer a range of passenger experiences and delivery options to meet widely varied needs at differentiated price points.

The earliest, most avid adopters are likely to be urban commuters. This community will benefit from quicker door-to-door trips due to efficient traffic from reduced start/stop and distances between vehicles, eliminated time spent searching for parking, and efficient routing informed by real-time awareness of weather and safety conditions. As smart infrastructure expands and self-driving cars near a tipping point, fleets of automated shared vehicles could spread from urban centers to densely populated suburbs and beyond. Automation enables more intelligent control and coordination systems, dramatically reducing the risk of accidents.

Additionally, advanced communication technologies could enable more efficient resource allocation (e.g., vehicle fleet, transportation mode choice, access point) while coordinating the customer's pointto-point mobility experience. The highly increased access to mobility in this future state has the potential to incent travel. 



\section{Mobility Futures-Energy Implications}

The following sections share observations and insights about potential aspirational and cautionary energy aspects related to three of the aforementioned non-incremental future states, namely:

\section{Personal-Automated, Shared-Mobility and Shared-Automated.}

By recognizing both the aspirational and cautionary energy outcomes of each future, this report is able to set context for future analyses, EERE R\&D and program priorities, and establish a foundation for collaboration with public and private stakeholders.

\section{Personal-Automated}

A Personal-Automated future anticipates that startups and established players have made automated technology ubiquitous within all vehicles, and the personal vehicle ownership model prevails.

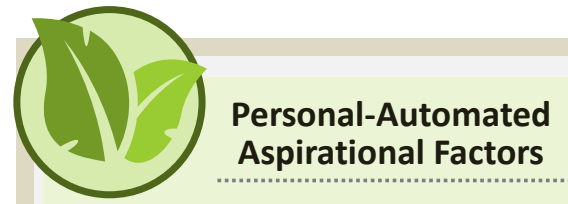

- VMT growth curbed by V2X tech that enables efficient-routing and traffic management decreasing commuting distance and time

- Suburbanization is stymied as urban design and land-use patterns encourage urbanization

- Policies and incentives for zero-emissions vehicles (ZEVs) are consistent, understandable and transparent

- Well-coordinated rule tightly regulate zerooccupancy vehicle use

- Powertrain efficiencies gained from predicative capabilities, platooning, and eco-driving

Technology - L Light weighting boosts efficiency and drives down operating costs

- Extended range and faster fill rate for alternative fuels allow ZEVs to predominate the market

\section{Personal-Automated Cautionary Factors}

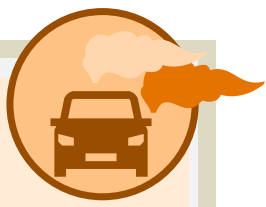

- VMT growth explodes due to increased tolerance and value of time spent commuting or in a vehicle

- Urban density decreases due to suburban sprawl; faster, farther commuting, increases VMT

- Policies and incentives for zero-emissions vehicles (ZEVs) are hidden, not aligned on federal, state and local level, or contradictory

- Zero-occupancy vehicles are not regulated to account for VMT and emissions

- Powertrain efficiency limited by demand for more performance features (e.g., faster, further)

- Safety concerns prohibit significant weight reductions or are offset by performance enhancements

- Limited range and slow fill rate for alternative fuels allow ICEs to predominate the market

Figure 5. Aspirational and Cautionary Energy Outcomes of a Personal-Automated Future 


\section{Aspirational}

In a Personal-Automated future, aspirational outcomes include automated features that deliver powertrain efficiencies, mature low-carbon technologies that can meet consumer range and refueling rate expectations, coordinated and effective policies that disincentive unwarranted use of zero-occupancy vehicles, and the existence of inherent upper bounds on the amount of time consumers are willing to spend commuting or in a vehicle.

Automated travel has tremendous potential to shape the urban and suburban landscape of 2050. In this future, driving time becomes 'unlocked' through automated technology, and the experience is made more enjoyable and safer through crash avoidance technologies and fewer traffic issues, significantly reduce that time spent and energy wasted idling in traffic.

Predictive modeling, platooning, and improved eco-driving could allow for optimized powertrains and greater vehicle efficiencies. Additionally, the improved safety features and crash-avoidance technologies could enable greater lightweighting, allowing vehicles shed the weight of "armor" no longer required, leading to improved efficiencies.

These efficiency gains could be compounded with adoption of zero-emission vehicles (ZEVs), which are made more attractive through falling battery costs combined with increasing range and performance, as well as lower cost fuel cells. Purposeful policies and incentives for ZEVs could further their adoption into the market. In a Personal-Automated future, the potential to decouple energy consumption from carbon through ZEVs is highly attractive to limit emissions impacts of higher VMT that automated travel could afford.

For example, in this future, vehicles could have the ability to find their own parking, return home once their passenger has reached a destination, or even run errands for their owners. This could lead to added strain on the capacity of the overall system with vehicles conducting additional trips per day. Purposefully crafted regulations and policies could safeguard from unbridled use of these personal zero occupancy vehicles, avoiding dramatic increases in unnecessary VMT.

While there are a variety of forces that could drive up VMT, it's possible, that most people-in the driver's seat or not-have limits as to how much time they are willing to spend commuting or in a vehicle. If spending time at home with family, living close to friends, or being able to have a night at a restaurant without having to spend an hour in a car is preferred, for example, this could establish upper limits on projected total VMT increase.

Additionally, purposeful urban design and land-use patterns, such as walkable communities, could allow closer proximity and accessibility to work, play, and other entertainment options, and negate demand for travel. 


\section{Cautionary:}

In a Personal-Automated future, cautionary outcomes include dramatic suburban sprawl made possible by a radically different commuting reality, heightened focus on performance and less efficient design, limited increase in powertrain efficiencies, continued predominance of internal combustion engines (ICEs), and exploding zero-occupancy trips.

In this future, the benefits of "unlocked" travel time, such as increased crash avoidance and fewer traffic issues, could enable significant increases in VMT, especially if the bounds of time spent in the vehicle are increased due to greater access to entertainment features (e.g., computers, televisions) or the ability to do work on the commute.

Much longer commutes may become the norm, especially if catching up on sleep or making the morning's calls can be done while the automated, self-driving system navigates the open road. More open, luxurious interiors might begin to resemble a living room or office space rather than traditional vehicles, as designers cater to the long-range commuter.

Additionally, as travel distances surge, consumers could demand increased range from their vehicles. Without technological breakthroughs increasing the range of ZEVs, or aligning incentives, ICEs could be positioned, with high-fuel capacity and quick refueling capability, to continue to dominate vehicle market share. Pressure from consumers for faster vehicles traveling longer distances could stifle broad investment in developing and manufacturing alternative fueling solutions, which could face unfavorable market conditions.
An increase in VMT from longer commuting distances could further be compounded by zero occupancy vehicles. Zero occupancy vehicles clearly present a value to the consumer in the form of newfound freedom. However, in this cautionary future, a lack of purposefully crafted regulations and policies could forego necessary safeguards from unbridled use of personal zero occupancy vehicles and could dramatically increase unnecessary VMT. Also, these unnecessary trips could put increased strain on the capacity of the system, resulting in a backlash of heightened congestion and choked roadways, further eroding any efficiency gains.

Historically, automotive safety concerns have been paramount with manufacturers, regulators, and consumers. Indeed, some have characterized the rise in vehicle weight as an "arms race," with each subsequent model year adding protective armor. If the potential accident-avoiding capacity of automated technology is fully realized, traffic accidents could become less and less frequent. Vehicle weight reduction-and the associated reduction in energy and emissions-is not guaranteed, however. 
Passengers' added time in the vehicle could create demand for new features, which could add weight and displace the savings, for example, more luxurious interiors and new vehicle design principles. Additionally, as driver safety rises significantly with the advent of automation, much higher speed limits become feasible. Energy savings could be redirected in order to satisfy consumers' desire for higher vehicle performance, potentially eliminating energy efficiency gains.

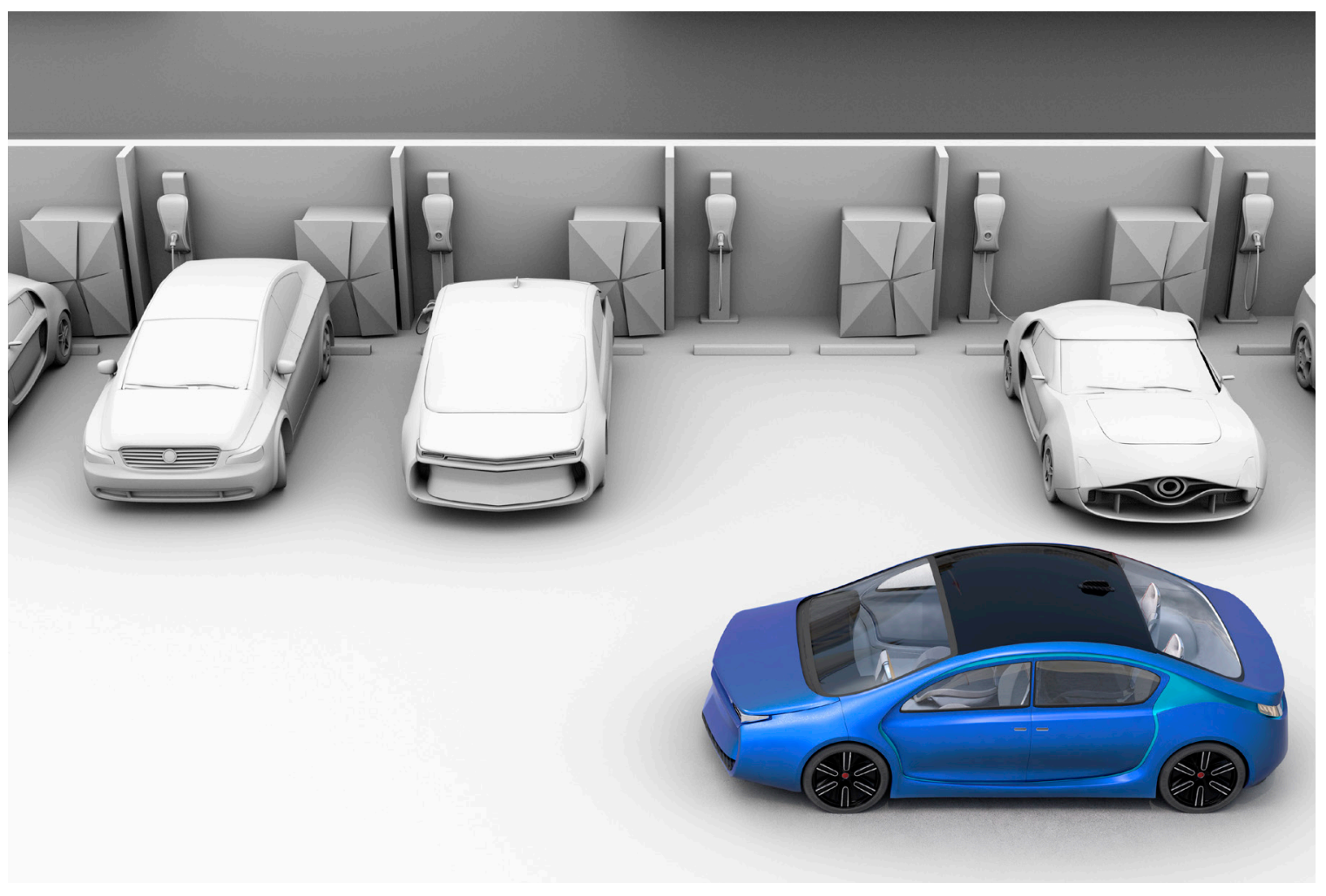




\section{Shared-Mobility}

A Shared-Mobility future anticipates that startups and established players have transformed the landscape to make shared ride services and on-demand mobility the dominant modes of personal transportation and delivery; however, in this state, connectivity remains limited (e.g., 4G or 5G), and vehicles remain short of fully automated . Notably, multiple vehicle ownership models (e.g., personal leasing or ownership; fleet operator) exist in this future; however, sharing is inherently built into the fabric of society and operations are strictly within a sharing context.

\section{Marketplace}

\section{Policy}

Technology

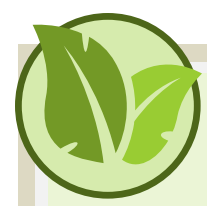

\section{Shared Mobility Aspirational Factors}

- VMT mitigated by higher occupancy trips and efficient routing

- Congestion is mitigated by increased traveler throughout

- Vigorous competition by multiple service providers increases vehicle and system efficiencies

- Curbside parking spaces are re-purposed to create shared-only lanes, plus expanded curbside access

- High occupancy trips and efficient modal shifting (higher occupancy transit) are promoted

- Vehicles are manufacturing for swappable, updatable components; replacement becomes far more simple and cheap

- Trip specific vehicle choice reduces energy consumption with smaller, more efficient vehicles

\section{Shared-Mobility Cautionary Factors}

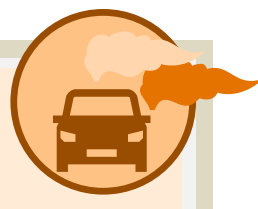

- VMT increased due to entrance of new user groups into the market (unserved; underserved)

- Higher congestion driven by increased demand and pull from higher-occupancy travel

- Market dominance by limited actors reduces competition and limits focus on efficiency

- Preservation of private parking land-use occurs, with limited re-design for shared features

- Single-occupancy trips are preferred and and inefficient modal shifting emerges

- Safety concerns limit manufacturing design for swappable parts (e.g. battery)

- Trip-specific vehicle choice becomes prohibitively expensive per unit due to small manufacturing runs

Figure 6. Aspirational and Cautionary Energy Outcomes of a Shared-Mobility Future 


\section{Aspirational}

In a Shared-Mobility future, aspirational outcomes include predominance of higher occupancy trips, purposeful policies to increase coordination with multimodal options, affordable manufacturability for higher utilization, increased market pull for low-carbon technologies, and availability of trip-specific vehicle choices.

Relatively lower costs and flexibility from shared mobility (e.g., mobility on-demand, ridesharing, bikesharing, carsharing) is likely to increase travel demand-notably by providing access to new user groups, such as those who face mobility challenges (e.g., elderly, disabled, and youth). However, high occupancy trips could provide a dual benefit of reducing congestion, increasing passenger throughput versus vehicle throughput and recouping efficiency gains from improved traffic flow and reduced idling time.

Additionally, an emphasis on passenger throughput could bolster ridership in traditional forms of mass transit. Increased number of strategic partnerships between flexible shared mobility companies and mass transit agencies could connect more consumers to access nodes for higher density transit, providing a viable solution to the 'first-mile, last-mile' problem. This shift enables streamlined, efficient multimodal travel, improving accessibility, and affordability for consumers. Investment in mass transit infrastructure benefits, as the two modes coalesce to provide complementary services.

The trend towards higher occupancy trips could increase as more vehicle ownership and operation is moved away from individuals toward fleet operators, who wield significant buying power and demand high-efficiency vehicle designs. As competition increases, fleet operators as a whole value efficient, safe driving in an environment of shared vehicles, and an increase in higher occupancy rides.

The shift in buying power away from individuals to large-fleet owners could also promote modularity (e.g., replaceable, updatable components) in vehicle designs, providing an impetus for rapid vehicle innovations and sparking manufacturer competitiveness around the beneficial aspects of modularity. With vehicles designed for high-utilization and shared-use applications, new technologies and features could be swapped into "older" vehicles that continue to operate, permitting vehicles to inexpensively keep pace with efficiency gains and reduce the energy consumed in manufacturing an entirely new vehicle.

Additionally, fleet operators bring their considerable buying power to bear, creating increased market demand for ZEVs that make prudent economic sense with falling costs of vehicle electrification and more affordable, less volatile, and low-carbon energy sources. Additionally, the pay-back period for low-carbon technologies significantly improves in a highly utilized shared fleet. As such, the aspirational future sees high penetration of ZEVs with investment in infrastructure to follow. The economics for ZEVs are further compounded by high occupancy trips with costs distributed over multiple passengers.

In this future, new urban designs and land-use schemes emerge to re-enforce the shared mobility ecosystem, and dramatically increase traveler throughput. For example, parking spaces are set aside for carsharing, street curbs are designated for mobility on-demand service pick-ups, and traffic lanes are reserved for ridesharing and higher occupancy vehicles. Additionally, the total number of parking spaces could shrink in number, allowing this space to be reclaimed for green spaces or parks, and biking lanes.

A Shared-Mobility future also drives a 'right-sizing' of the nation's vehicle fleet. Contrary to the personal-ownership model, where customers typically purchase a vehicle to meet multiple functions, with access to a shared pool of vehicles, customers are now able to secure vehicles or services appropriate for a specific task or journey. Similar to penetration of ZEVs, increased utilization rate speeds up payback for various vehicle types within a fleet. Additionally, this higher efficiency of assets reduces overall energy consumption when spread across the entire vehicle fleet. 


\section{Cautionary:}

In a Shared-Mobility future, cautionary outcomes include predominance of low-occupancy ridership, increased frequency of point-to-point trips leading to increased congestion, limited powertrain efficiencies and vehicle redesign, stifled competition with only a few dominant market players or fragmented ownership models limiting system-wide efficiency gains, smaller manufacturing runs making right-sized, trip-specific vehicle design prohibitively expensive, and limited urban redesign.

In this future, the added convenience of point-topoint travel may draw riders-both existing and new market entrants-away from more energy-efficient modes of transportation, such as mass transit, biking, and walking. This effect is compounded if higher-occupancy trips (e.g., ride splitting, microtransit) are limited, and consumers prefer single-occupancy trips, which cannot spread emissions over many riders. Additionally, increased single occupancy point-topoint trips, verses higher occupancy trips, could increase congestion and choke roadways.

Powertrain optimization and radical vehicle design is limited in a Shared-Mobility future with human drivers. As is the case with any driver, the overall vehicle efficiency is determined by driving style (e.g., acceleration styles, braking styles). Continued reliance on a driver to operate the vehicle diminishes the types of efficiency gains from eco-driving, predictive modeling, and platooning (or drafting), as well as vehicle design, that could be achievable in an automated future.
In a Shared-Mobility future, it's possible that multiple ownership models may exist to meet the needs of mobility services. Individual drivers may continue to own or lease their own vehicles and operate on a fleet platform. Fragmented ownership models could limit the buying power and fleet-wide optimization with a fleet operator, who would have a greater incentive to deploy low-carbon vehicle technologies, and invest in and use predictive analytics and real-time information, further improving upon today's capabilities for plotting travel routes, mapping vehicle distribution, setting pricing, and dispatching orders. Missed opportunities to reduce emissions could result from a failure to fully develop an optimal system for data collection, sharing, and analysis.

Additionally, manufacturing costs may become prohibitively expensive for trip-specific vehicles, as economies of scale and small manufacturing runs make per unit costs higher. For example, if the majority of demand is for vehicles with one or two seats, manufacturing a vehicle with four or six seats for use on rare occasions could be prohibitively expensive. Compounding costs per vehicle also includes manufacturing design for increased durability. As fewer vehicles assume a larger portion of the transportation demand, vehicles will be manufactured for durability and higher lifetime utilization rates. However, safety concerns may prohibit manufacturing design for swappable parts, increasing costs per vehicle.

Finally, the shift to Shared-Mobility could allow more integrated land-use planning; however, in a cautionary future, demand for parking space persists as individual drivers retain ownership or lease their vehicles from fleet operators, and, therefore, continued availability of parking spaces would be required. Additionally, without automation, existing size of roadways and streets will persist without significant opportunity for redesign. 


\section{Shared-Automated}

A Shared-Automated future anticipates a convergence of automation and shared mobility trends.

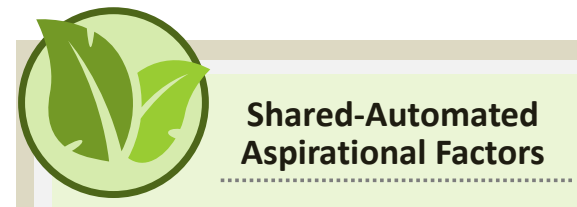

- VMT limited by inherent upper bounds on time spent commuting or in a vehicle, and

Marketplace

Policy

Technology partnerships with other transportation modes (e.g., walking, biking, and mass transit)

Urban redesign and land-use adjusted for multimodal and efficient transportation

- Data is shared but monitored to protect the consumer. Public sources share data freely, and accurately, with no privacy risks to consumers

- Customers have consistent safety and service, mechanisms are in place to ensure enforcement

- Dedicated short range communications (V2X) are ubiquitous; connectivity improves safety, provides real-time data on fleet movement and position

\section{Shared-Automated Cautionary Factors}

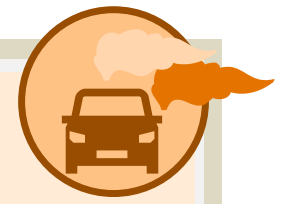

- VMT significantly increased due to negation of the last mile problem and shift away from alternative forms of transportation (e.g. walking, biking, and mass transit)

- Urban redesign and land-use preserved or expanded for vehicle-only travel

- Customer requirements allow vehicle and powertrains designed for efficiency

- Efficiency gains and high utilization bolster economics for ZEVs
- Data is not shared for public benefits; no oversight of private companies' use and sharing of data

- No common standards are established for services; comfort experiences vary widely

- Dedicated short range communications (V2X) are not ubiquitous; connectivity is limited in use due to cost, functionality, and integration barriers

- Vehicles and powertrains designed for performance in lieu of more efficiency

- Drive/duty cycles favor efficiency gains for ICEs and diminish return on investment for ZEVs

Figure 7. Aspirational and Cautionary Energy Outcomes of a Shared-Automated Future

\section{Aspirational}

In a Shared-Automated future, the positive aspects of shared mobility and automation could combine in a future to yield several disruptive features that reduce energy consumption and GHG emissions. In this future, aspirational outcomes include compounding economics to support penetration of ZEVs and investment in alternative fuel infrastructure, radical vehicle redesign and powertrain optimization, ubiquitous adoption of sophisticated information management systems and short-range communication (V2X) to increase vehicle safety as well as traffic and route efficiencies, and dramatic urban redesign and land-use shifts to promote multimodal and efficient transportation options while increasing accessibility and mobility.
In this future, higher utilization and subsequently faster payback, combined with efficiency gains from powertrain design, could strengthen the economics for ZEVs. Without the cost of the driver, the price per ride could fall to a point that enables more trips and therefore, reducing the payback period more quickly than even a Shared-Mobility future. For managers of automated fleets (e.g., shared mobility service providers, fleet operators, or manufacturers), these compelling economics combined with the business incentive to deliver low-cost operations will increase the market demand pull for the development of alternative fueling infrastructure and ramped-up production of affordable ZEVs. 
Additionally, shared, self-driving vehicles present an opportunity to open up the vehicle design space leading to drastic changes and 'right sizing' more broadly applied than in the Shared-Mobility future due to removal of the driver. Customer requirements, and prudent business decisions from fleet operators, allow powertrains to be designed for efficiency. These smaller, more finely tuned, drivetrains emerge in all vehicles and save interior space, reduce operational costs, and create a more amenable experience for passengers focused on things other than driving.

These benefits from optimal powertrain design are further enabled by more efficient driving from automated features, including predictive capabilities and eco-driving, similar to Personal-Automated. Strong incentives for fleet operators to take advantage of these features foster cooperation within the industry to develop protocols, standards, and uniform requirements for technology providers.

Ubiquitous adoption of sophisticated information management systems and short-range communication (V2X) could provide much needed data sources on travel patterns and traffic flows, as well as increased safety features (e.g., crash avoidance) to mitigate congestion. With proper protocols established to protect sensitive information, data from automated vehicles are carefully managed, creating powerful solutions to improve the Shared-Automated future. Appropriate standards, protocols, and oversight ensure secure data collection, storage, and use, sparking new technologies and analytics applications that further optimize mobility system operations. This data is further used to develop more accurate and efficient real-time routing capabilities, enabling more streamlined traffic flows, further squeezing energy efficiencies from the system.

Shared and automated features could also lend themselves to stronger alignment with mass transit options. For example, geo-tagged neighborhoods serviced by mobility on-demand rides could provide more flexible, cheaper connections to mass transit nodes. Strategic partnerships could develop between mobility services providers and traditional mass transit agencies, similar to Shared-Mobility, but at much more affordable price-points, enabling greater accessibility and service areas. Access could expand beyond high density urban environments to connect more suburban and rural areas.

In a Shared-Automated future, more substantial re-design of the urban landscape occurs. Intersections could be reorganized to facilitate foot traffic, as automated technology eliminates traditional stoplight schemas. Less parking (and driving to find parking spaces) unlocks significant tracts of urban land, incentivizing biking or walking infrastructure to take the place of roadside parking spaces. Throughput significantly increases as automated features permit safe operation on narrower traffic lanes at much higher speeds.

Purposefully planning to better connect work, home, and recreational activities could also increase accessibility and negate demand for miles traveled. This trend combined with possible limitations on human willingness to spend time in a vehicle or in transit could further curb VMT.

\section{Cautionary}

In a Shared-Automated future, cautionary outcomes include drive cycles and duty cycles that favor ICEs and diminish incremental returns for ZEVs, consumer demand for vehicles and powertrains designed for performance, limited penetration or penetration of non-standardized information management systems and short-range communication (V2X), urban redesign solely around vehicle-only travel, and significantly higher VMT from increased short-range point-to-point travel as well as displacement of other high density regional travel modes.

While the trends toward ZEVs in Shared-Automated future is compelling, it is possible that the efficiency gains from automated features that result in smoother profiles, including predicative capabilities and eco-driving, could actually increase the efficiency and attractiveness of ICEs relative to ZEVs. With a narrower gap between ICE and ZEV efficiencies, the return on investment through total cost of ownership savings may be marginalized even with a higher utilization factor resulting in diminishing returns for ZEVs. This could also be compounded if alternative fuel infrastructure proves to be an added cost versus leveraging existing infrastructure. 
This cautionary viewpoint, which is counter-intuitive to the notion that shared-automated vehicle economics inherently favor ZEVs, could severely curb efforts to introduce more ZEVs into the market with an economy-wide impact on emissions reductions. Additionally, in a cautionary future, vehicle and powertrain efficiencies could be limited as customer requirements focus toward design for performance. This customization becomes an appeal to reach new market segments and differentiate brands of various shared mobility providers.

Dedicated short-range communication (V2X) is essential for ensuring the safety of vehicles and travel efficiency experience limitations on functionality (interoperability, protocols, data sharing) along with persistent cost and ownership concerns that limit significant investment in necessary 'data infrastructure'. With no 'eyes and ears' to enable orchestration of the shared, autonomous mobility system, the full promise of safety and convenience fail to materialize. Additionally, without access to transparent and accurate data, real-time traffic and routing efficiencies could suffer.

With steering wheels removed from human hands and entrusted instead to fleet operators and automated drive algorithms, massive amounts of vehicle and passenger data are collected. These data can be a powerful resource; however, lack of coordination and transparency between industry and public transportation agencies could prevent or delay advancements that could reduce sector emissions. Likewise, unmonitored private companies entrusted with sensitive information contained in broad data sets potentially expose consumers to unacceptable risks from privacy breaches.

In this future, VMT could increase sharply due to significant reduction in labor expense, namely the driver, making cheap travel ubiquitous. Building on the cost reductions achievable through shared vehicles and ridership, automation lowers costs to the point where vehicle transportation becomes cost-competitive with existing, regional transportation modes, such as rail and airplane. Planes and trains face new competition for regional travel, as consumers abandon higher-density (and higher cost) travel options.
This switch is made more attractive as consumers take advantage of automated controls, sophisticated communication capabilities between vehicles and infrastructure systems, self-driving vehicles travel at much higher speeds, allowing great distances to be traveled over a short-time period, or shorter trips to be achieved even quicker. On a local scale, pressure is placed on mass transit and non-automotive modes of transportation, such as biking and walking. Urban design and land-use preferences could cater to vehicle-only travel, negating opportunities to encourage other modes.

Unlike in an aspirational future, it's possible the ubiquitous availability of flexible, affordable mobility in vehicles may prevent synergies with other forms of mass transit, which require fixed time and routes. By circumventing the 'first-mile, last-mile' problem entirely with point-to-point travel at an affordable price point, Shared-Automated options significantly decrease ridership of mass transit. The more singular-reliance on automotive vehicles for travel could also influence urban re-design and land-use, displacing efforts to strengthen symbiotic relationships with alternative forms of transportation (e.g., transit, walking, biking). Additionally, to meet this sky rocketing demand, the overall size of the vehicle fleet could proliferate, increasing demand for more capacity and roadways. 


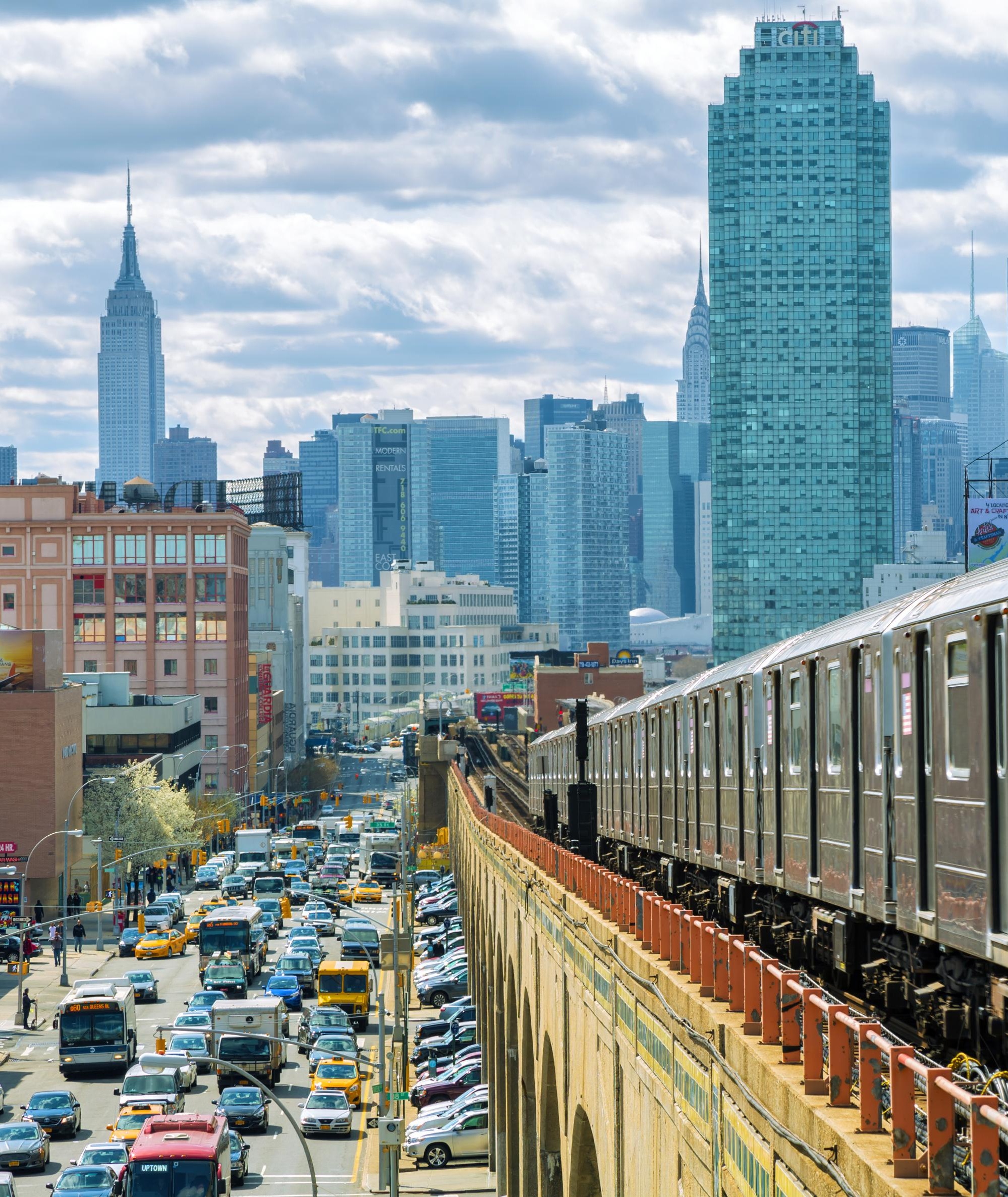




\section{Ripple Effects}

This paper primarily focuses on the direct energy and indirect "rebound" effects, such as increased VMT, that can transpire as a result of automated and shared mobility. However, there are many other ripple effects that emanate from this epicenter of transformative change that can have non-trivial effects on energy consumption and emissions, as well as the trajectory for underpinning of technologies, R\&D, product requirements, supply chain, and US manufacturing competitiveness.

For example, how will new value creation drive energy consumption? How will product requirements change to meet customer needs? What will be the trajectory for future R\&D? And, how will all of this disruption impact the supply chain and US manufacturing competitiveness? These ripple effects in the mobility ecosystem are critical factors when looking at the full potential of economy-wide energy and GHG emissions impacts.

\section{The Perfect Storm-Nexus of Low-Cost Personal and Goods Mobility}

The potential for ubiquitous, cheap travel of people and goods, combined with new spending capabilities, could dramatically increase VMT related to goods movement. Currently, our nation's 240 million vehicle light-duty fleet is utilized only $4 \%$ of the time, representing trillions of dollars of value tied up in vehicle assets, the value of the real-estate to park them, and the time spent to drive them. Admittedly, it is this existing inefficiency that is drawing countless new entrants into the mobility space with the aim to create, deliver, and share new found value that has the potential to enhance our productivity, accessibility, safety, and quality of life.

This could be a tremendous injection of value creation into our economy. Foregoing car ownership could dramatically improve discretionary income for many. Transportation is the second largest household expense. Switching to shared mobility options, especially if combined with automated features, could dramatically reduce this burdensome cost and enhance discretionary income and savings, while maintaining or increasing mobility and access.
What remains unclear is will consumers save more or will they simply consume more? We've already discussed the potential increases to personal travel as measured by VMT and the potential for inefficient modal shifting, which is possible within all cautionary energy futures. The potential ripple effects on goods delivery, however, must also be considered as business leverages the benefits of shared and automated features to dramatically reduce costs. The lower price point, coupled with increased discretionary income and convenience of e-retailing at our fingertips from our smart devices, may drive an explosion in VMT for goods delivery. The impacts may be further compounded by automated technologies, which free up the driver's hands and travel time for other activities.

So in this nexus of new value creation, falling costs of travel for personal mobility, and analogous transformation in goods movement, the potential energy ripple effects in our mobility ecosystem could be profound.

\section{Letting Go of the Wheel-No More 'Pedal to the Metal'}

What happens to the mobility ecosystem when you remove the steering wheel from the hands of the customer, whether in a Personal-Automated or Shared-Automated future? A driver has a variety of needs related to performance, handling, "noise, vibration, and handling"(NVH), human-machine interface, fuel economy, durability, reliability, and host of other considerations related to his or her personal driving style and vehicle preferences.

However, once the driver is now a passenger, do those same considerations still matter? If today, we started to design a vehicle for use in 2050, will we still need heavy low-end torque, wide-open throttle, and pedalto-the-metal acceleration? Do we still need extreme horsepower for aggressive passing maneuvers? What level of performance will be needed to navigate traffic, safely steering clear of harm's way, and traverse the occasional mountain drive? Furthermore, if fleet operators are the primary owner and operator of vehicles, how might their specific needs influence product design? 
As previously discussed in both cautionary and aspirational futures, the application of the vehicle (shared, not shared), and existence of automated technology features will have an impact on vehicle and powertrain design. To match emerging product requirements, especially across varied environments of shared, automated, or both, we could see radical redesigned vehicle architectures, right-sized vehicles, with powertrains aligning to those new vehicles drive and duty cycles.

\section{The Invincible Pod That Could-Life of a Battery}

In an aspirational future, all vehicles may likely have electrified powertrains connected to low-carbon energy sources. However, similar to how the application and use of the vehicle will impact the design and performance requirements, it will also determine the subsequent requirements for battery performance (e.g., energy density, power capability, cycle life, and recharge rates).

Is the ultimate goal a shared-connected-automated-electric pod that is capable of providing virtually non-stop service that comes with a 300,000-mile powertrain warranty? The requirements will depend on if it is a Personal-Automated, Shared-Mobility, or a Shared-Automated future. For example, is a sub $\$ 100 /$ kWh high-density, slower-charge battery with a 200-mile range the right fit for a high-utilization pod? What if a more expensive battery with balanced energy density and ultra-high charge rates could minimize the time out of service and maximize up time of shared vehicle assets? What would that battery look like? How much could it cost and still provide a return on investment?

Given the multitude of different applications, and varied needs and performance requirements, future battery R\&D must be able to comprehend, and respond to all of the potential outcomes. The right solution for specific-use applications will have further ripple impacts on the capital efficiency of fleets, or personal vehicle owners, and the charging infrastructure requirements. Currently, the majority of consumer charging needs are met at the home or workplace; however, this may not be sufficient in a fully shared model when vehicles are highly utilized during all periods of the day and night and must maximally remain on the roads in revenue service.
The changes in drive and duty cycle will also affect major component designs, such as battery packs, cells, thermal management, chemistry, and manufacturing, as well as energy efficient technologies, such as drivetrain and lightweight materials. Achieving an aspirational future will require setting the right research targets and focus, and ensuring compatibility with the electricity grid and the arrival of low-carbon energy sources.

\section{Supply Chain Disorientation-Streamline for Success}

Integral to achieving an aspirational mobility future will be the success of managing and understanding the impacts on the supply chain. How the transportation system evolves along the lines of shared and automated technologies will impact the annual volumes, size of the fleet, and subsequently, the supply chain currently designed to support a 240 million vehicle light-duty fleet.

Major industry volume adjustments are possible in either direction. For example, as previously mentioned, significant disruption, particularly in an increasingly shared future with higher utilization rates and diminishing incentives for private vehicle ownership, could drive down annual sales volume and reduce overall size of the vehicle inventory. Following a period of disruption, the sales volumes may eventually recover, as higher utilization causes faster turnover of vehicles, and thus require replacement.

Conversely, demand for increasing durability could offset higher turnover rates, and a rebound affect does not occur, resulting in a major shift downwards in industry volume in the long term.

As a consequence, lower volumes drive costs up through the entire supply chain and could impact costs for mobility. On the other hand, sky rocketing demand and a need to increase capacity for new trips could drive up vehicle inventory. This could exist in a future with combinations of private ownership and higher-turnover shared assets.

The speed at which vehicles are cycled out of the fleet would have a consequential impact on the ability to increase turnover of new technologies and upgrades.

As a result, product development cycles may shorten, and payback for new components, such as batteries, 
accelerated, increasing the tolerance for varied price points. For example, a shorter three year battery life could lead to increased replacement rates, resulting higher capacity utilization of battery plants as more batteries are produced sooner to meet demand. Similarly, durability needs and higher utilization factor pull through premium durable, lightweight materials, such as carbon fiber composites.

\section{US Manufacturing Footprint-Strengthening Compet- itiveness in Mobility Futures}

Notably, the potential value creation in the mobility space is attracting new entrants into the market, including from non-adjacent industries, such as consumer electronics. Many of these companies have existing supply chains and manufacturing models that focus on technology innovation within the US, while locating manufacturing and supply chains overseas. With these new market entrants gaining prominence, could disruption in the mobility system or commoditization of transportation assets lead to displacement of US manufacturing?

This trend could be exacerbated by significant purchasing power by fleet operators who drive extreme price competition to leverage the lowest cost manufacturing. Conversely, will other product requirements, such as increased durability, reliability, and quality, become more important than low upfront costs? And will proximity to technological innovation be a key focus for manufacturers as product development cycles compress and align to match the heightened pace of change?

The key takeaway to consider is that a disruption in the mobility ecosystem could have ripple effects all the way down to choice of manufacturing location and overall US manufacturing competitiveness.

\section{Shared Automation Prolongs Dominance of ICEs-} Transitioning to a ZEV Future

Emerging consensus among industry leaders says that the economics become increasing compelling for ZEVs within a shared mobility future, particularly a shared and automated future. Reduced operating costs and increased utilization rates all play toward faster payback periods and increasing returns for the asset. However, these gains and payback periods are currently based in comparison to today's ICEs and drive cycles.

What if these same gains increase the efficiency and attractiveness of operating a fleet of ICEs and lead to diminishing returns, in comparison, for ZEVs? Could all of our assumptions about the benefits from these new transportation modes actually continue and strengthen our reliance on ICEs?

If the presumed best-case trajectory for low-carbon transportation is electrified powertrains tied to low-carbon energy sources, could advancement into a shared, automated future prevent the achievement of that goal? Further analysis will be required to study how to enable a transition to the lowest carbon, sustainable mobility future. 


\section{Avoiding a Revenue Drought-How to Pay for a New Mobility Paradigm}

The growth of shared and automated vehicles could have potentially dramatic impacts on public sector budgets and revenue sources at the federal, state, and local level. Today, many public sector budgets rely on revenue generated from the existing transportation system, for example, the gasoline tax, parking permits, parking tickets, parking meters, speeding tickets, vehicle registration fees, and drivers licenses. This revenue is used to pay for upgrades and maintenance of the system, as well as finance discretionary budgets.

However, in a Personal-Automated, Shared-Mobility, or Shared-Automated future, particularly with ZEVs, these revenue sources could face steep deficits. What if there is no longer a need for parking meters or parking permits, or how will local traffic enforcement give tickets to an automated vehicle that never breaks a traffic rule?

And what about the impact on public transit budgets? If new transportation modes emerge that draw on mass transit ridership, how will operators recoup expenses, make necessary upgrades, justify capital costs for rolling stock, and maintain quality and level of service to those who continue to need access to public transit?

A potentially vicious cycle could emerge as more and more people choose alternatives to public transit options, resulting in loss in ridership, further lowering operating cost recovery and curbing utilization of rolling stock. This downward spiral could lead to further consolidation of rolling stock and less frequent service to bolster utilization, ultimately resulting in lower levels of service and compounding the departure to alternative mobility solutions.

These are important factors to consider, especially as significant investments in infrastructure will be required to achieve an aspirational future.

\section{Job Dislocation - Direct and Indirect Impacts}

The rise of shared mobility and automation could have significant impacts on the existing transportation industry workforce as well as in adjacent sectors.

As part of this transformation, there will likely be job dislocation effects and reallocation of those sources of income, leaving some disproportionately impacted in a future paradigm. For example, drivers of all types (e.g., truck, taxi, bus, train, parcel delivery, and on-demand mobility), auto body shops, towing services, insurance, emergency response, and many other associated occupations could experience direct and indirect job effects.

In an increasingly shared mobility future, anyone with a driver's license and access to a vehicle (personal ownership or rented) could be employed with heightened flexibility to choose when, where, and for how long they work. In contrast, a fully automated future could see the most apparent effect on dislocated jobs. This dislocation, however, is likely accompanied by new job creation and growth in other areas (e.g., software engineers, data scientists, and machine-learning experts). For example, new engineering and vehicle design could support a growing technology and manufacturing job base.

Additionally, this transformation could have broader societal and economic impacts. More affordable access to transportation could increase mobility and provide more opportunities for underserved portions of the workforce to access jobs that are currently prohibitively far away from where they live. More efficient use of transportation resources and less wasted expense related to congestion or accidents could be a catalyst for economic productivity and jobs. Additionally, higher discretionary income could spur economic growth that creates new jobs across multiple sectors (e.g., e-retailing, infotainment, and infrastructure). 


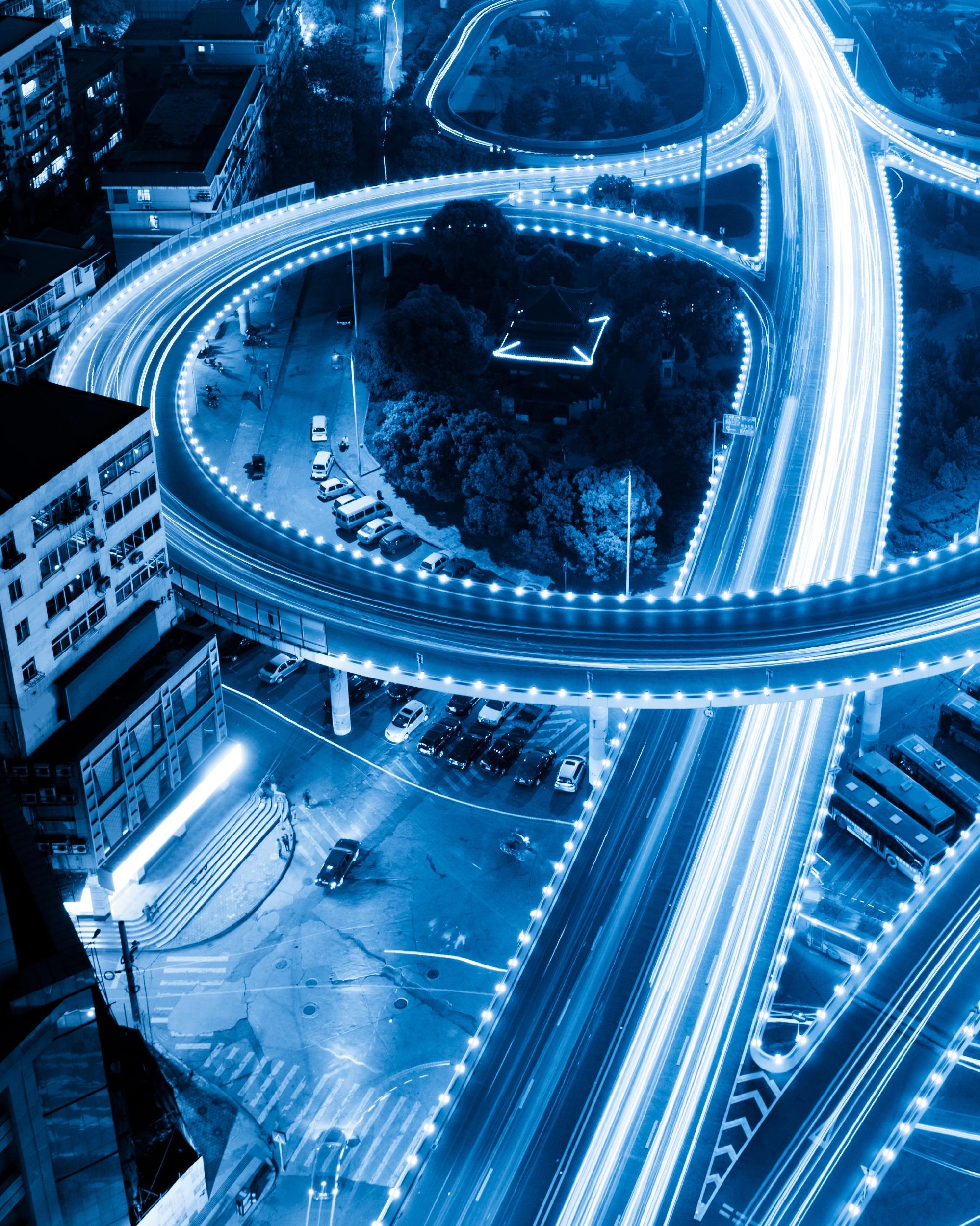




\section{Conclusion}

It is an incredible time to envision what is possible for the mobility system of the future. Given the complex set of economic and demographic factors converging with technological breakthroughs and changing consumer preferences, something truly transformative could emerge through heightened mobility and economic productivity.

This report served to specifically focus the conversation on what impact these new innovations and disruptions could have on future energy consumption and the broader economy. The hypothetical set of futures discussed in this report provide insights and observations into possible energy outcomes, aspirational or cautionary, of the changing mobility ecosystem, and serve as guiding principles for future research, analysis, and dialogue. Whether transformation will evolve incrementally or whether change will occur in a more rapid and disruptive manner remains to be seen, and how this future world develops will depend in large part on the development and application of advanced automotive and digital technologies, as well as the right market and policy forces to enable their adoption.

This report identified several key takeaways for an aspirational energy future, including:

- Higher-occupancy trips, efficient routing, and efficient modal shifting in a Shared-Mobility or Shared-Automated future could realize higher-efficiency gains and curb VMT;

- Unique market applications in a Shared-Automated future (e.g. shared fleet in an urban environment) could allow for vehicles to be designed for powertrain efficiency;

- Each future state could enable full penetration of ZEVs through consistent, understandable, and transparent policies and incentives.

- New manufacturing techniques could unlock the design space in a Shared-Mobility and
Shared-Automated future state, enabling far more simple and cheap replacement of parts to withstand higher utilization rates;

- Priority emphasis on shaping urban design and land-use around efficient transportation modes, including transit, biking, and walking, and reduced demand for parking infrastructure, especially within a Shared-Automated future, could unlock significant real-estate value and increase mobility within the urban center;

- Transparency and accuracy of data and ubiquitous arrival of dedicated short-range communications (V2X) in a Personal-Automated and Shared-Automated future could optimize efficiency gains at the fleet level.

Conversely, this report elicited stark reminders of the cautionary energy future that could emerge, including:

- Predominately single-occupancy and unwarranted zero-occupancy trips, combined with increased point-to-point trips that reduce ridership of higher-occupancy transportation options, could increase VMT and overall energy consumption;

- Continued vehicle design for performance could limit efficiency gains, as well as limited powertrain optimization;

- Drive and duty cycles in a Shared-Automated future could favor efficiency gains from ICEs and diminish return on investments for ZEVs;

- Safety concerns could limit manufacturing techniques and reduce penetration of lightweighting;

- Continued focus on shaping urban design and land-use for the vehicle-only transport, especially in an Shared-Automated future state, could shift emphasis away from more other symbiotic modes of transportation, including mass transit, biking, and walking;

- Limited use of short-range communications (V2X) in a Personal-Automated and Shared-Automated future could make automated travel less safe and limit efficiency gains at the fleet level. 
These considerations are by no means exhaustive, and as we progress towards these futures, new factors could emerge that could impact energy. The way people move in the future has the potential to be radically different and to provide the greatest societal benefits and aspirational energy outcomes, in whichever of the hypothetical future(s) emerge. Conversely, there is a risk that not all will be attainable, or some benefits will be realized but energy consumption will explode in the absence of a purposeful, guided approach. In addition, negative ripple effects (e.g., job displacement) will likely emerge in response to this transformation.

The challenge will be to align technology, policy, and market forces in order to achieve the greatest societal benefits and aspirational energy outcomes, in whichever futures emerge. This will entail continuing to work closely with private and public sectors to address the questions raised throughout this report, as well as future considerations that have yet to emerge. This will require input on which technologies require increased research and development support, how EERE should prioritize its research investments, and opportunities for EERE to better engage with industry, other agencies and stakeholders within the public and private sectors. Together, we can navigate our way towards the most aspiring and energy-efficient future that maximizes economic value creation and provides unprecedented safety, affordability, and accessibility to the American people. 


\section{Acknowledgements}

This report was developed by the contributions from:

- Courtney Hinkle, DOE Office of Sustainable Transportation

- John Cabaniss, DOE Office of Sustainable Transportation

- Jacob Ward, DOE Vehicle Technologies Office

- David Gohlke, DOE Vehicle Technologies Office

- Rachel Nealer, DOE Vehicle Technologies Office

Deloitte Consulting, LLP provided workshop support, subject matter specialists, and assisted in writing this report.

Additionally, the authors relied upon the hard work and valuable contributions of many stakeholders in government, industry, academia, and non-governmental organizations. We especially want to acknowledge the contributions of the following organizations in shaping the energy discussion around the evolving transportation sector:

\begin{tabular}{|c|c|c|c|}
\hline $\begin{array}{l}\text { Adam Stocker } \\
\text { Alex Schroeder }\end{array}$ & $\begin{array}{l}\text { University of California - Berkeley } \\
\text { National Renewable Energy Laboratory }\end{array}$ & $\begin{array}{l}\text { Katherine Kortum } \\
\text { Kev Adiemian }\end{array}$ & $\begin{array}{l}\text { Transportation Research Board } \\
\text { Idaho National Laboratory }\end{array}$ \\
\hline Ana Wagner & $\begin{array}{l}\text { DOW Automotive Systems | The Dow } \\
\text { Chemical Company }\end{array}$ & $\begin{array}{l}\text { Kirk Steudle } \\
\text { Kristen Pawling }\end{array}$ & $\begin{array}{l}\text { Michigan Department of Transportation } \\
\text { Natural Resources Defense Council }\end{array}$ \\
\hline Ann Schlenker & Argonne National Laboratory & Levi Tilleman-Dick & Valence Strategic \\
\hline Ariel Gold & US Department of Transportation & Lisa Snapp & US Environmental Protection Agency \\
\hline Art Guzzetti & American Public Transportation Association & Marc Winterhoff & Roland Berger \\
\hline Austin Brown & National Renewable Energy Laboratory & Marcia Pincus & US Department of Transportation \\
\hline Bob Burns & B-cycle, LLC & Margaret Taylor & Lawrence Berkeley National Laboratory \\
\hline Budhu Bhaduri & Oak Ridge National Laboratory & Mark Barteau & University of Michigan \\
\hline Carlton J Reeves. & US Department of Energy | Advanced & Mark Norman & Transportation Research Board \\
\hline Ph.D & Research Projects Agency - Energy & Mark Platshon & Icebreaker Ventures | The Autonomous \\
\hline Carrie Morton & University of Michigan & & World Fund \\
\hline Chris Borroni-Bird & Qualcomm & Melanie Crotty & Metropolitan Transportation Commission | \\
\hline Chris Gearhart & National Renewable Energy Laboratory & & Bay Area Toll Authority \\
\hline Colin McCormick & Valence Strategic & Mutaz Shkoukani & Key Safety Systems \\
\hline Colin Peppard & $\begin{array}{l}\text { Los Angeles County Metropolitan } \\
\text { Transportation Authority }\end{array}$ & $\begin{array}{l}\text { Myra Blanco } \\
\text { Nidhi Kalra }\end{array}$ & $\begin{array}{l}\text { Virginia Tech Transportation Institute } \\
\text { RAND Corporation }\end{array}$ \\
\hline Danil Prokhorov & Toyota Technical Center & Regina Clewlow, Ph.D & moovel \\
\hline David Klein & Moovit & Ron Faibish & Argonne National Laboratory \\
\hline David St. Amant & Econolite & Ryan Croft & TransitScreen \\
\hline Dawn Manley & Samsung Strategy and Innovation Center & Ryan Harrington & The Volpe Center \\
\hline Don Halligan & Baltimore Metropolitan Council & Scott Averitt & Bosch \\
\hline Don Mackenzie & University of Washington & Seth Mallen & Maximus Real Estate Partners \\
\hline Emily Stapleton & Motivate & Stephen Zoepf & Stanford University \\
\hline Emmanuele Spera & Next Future Transportation, Inc. & Steve Williams & Navistar \\
\hline Eric Wingfield & Ford Motor Company & Steven Shladover & California PATH \\
\hline Gerry Tierney & Perkins+Will & Sue Zielinski & University of Michigan \\
\hline Huei Peng & University of Michigan & Susan Shaheen & University of California - Berkeley \\
\hline Ian Schneider & Massachusetts Institute of Technology & Teresa Gaynor & Nauto \\
\hline Jane Macfarlane & Lawrence Berkeley National Laboratory & Victoria Waters & University of Michigan \\
\hline Jean Redfield & NextEnergy & William Chernicoff & Toyota Motor North American, Inc. \\
\hline Jim Saber & NextEnergy & William Peirce & General Motors - Research \& Development \\
\hline Joan Walker & University of California - Berkeley & Zachery Wasserman & Via \\
\hline Johanna Zmud & Texas A\&M Transportation Institute & & \\
\hline John Maddox & University of Michigan & & \\
\hline Jonathan Levine & University of Michigan & & \\
\hline Jonathan Sadow & Scoop & & \\
\hline Jonny Simkin & Swiftly & & \\
\hline Justin Fishkin & Local Motors & & \\
\hline Justin Holmes & Zipcar & & \\
\hline Karl Simon & US Environmental Protection Agency & & \\
\hline
\end{tabular}

${ }^{8}$ Disclaimer: any mention of a specific company or organization is not meant to imply an endorsement on the part of the US Department of Energy or the US Government. 


\section{References}

1. Barnhart, Wolfgang, Marc Winterhoff, Jan-Philipp Hasenberg and Ludwig Fazel. 2016. A CEO agenda for the (r)evolution of the automotive ecosystem. In, Think Act, ed. Cornelia Geissler, Munich: Roland Berger $\mathrm{GmbH}$.

2. Brown, Austin, Jeffrey Gonder, Brittany Repac. 2016. An Analysis of Possible Energy Impacts of Automated Vehicles. In Road Vehicle Automation 3, eds. G. Meyer and S. Beiker, 137-153. Switzerland: Springer International Publishing.

3. Corwin, Scott, Joe Vitale, Eamonn Kelly, and Elizabeth Cathles. 2015. The future of mobility: How transportation technology and social trends are creating a new business ecosystem. Deloitte University Press.

4. Energy Information Administration (EIA). 2016. Monthly Energy Review, September 2016. Washington, DC.

5. Gao, Paul, Hans-Werner Kaas, Detlev Mohr, and Dominik Wee. 2016. Disruptive Trends That Will Transform the Auto Industry. McKinsey \& Company.

6. Greenblatt, Jeffery B., and Samveg Saxena. 2015. Autonomous taxis could greatly reduce greenhouse-gas emissions of US light-duty vehicles. Nature Climate Change vol. 5, (July): 860-863.

7. Lancefield, David. 2016. PwC Issues: Megatrends. http://pwc.co.uk/issues/megatrends.html (accessed August 30, 2016).

8. Litman, Todd. 2016. Selling Smart Growth: Communicating the direct benefits of more accessible, multi-modal locations to households, businesses and governments. Victoria Transport Policy Institute (May 10, 2016). http://www.vtpi. org/ssg.pdf (Accessed August 30, 2016).

9. Martin, Elliot, and Susan Shaheen. 2016. Impacts of car2go on Vehicle Ownership, Modal Shift, Vehicle Miles Traveled, and Greenhouse Gas Emissions: An analysis of five North American Cities. Berkeley: University of California (Berkeley).
10. McKerracher, Colin, Itamar Orlandi, Michael Wilshire, Christer Tryggestad, Detlev Mohr, Eric Hannon, Eric Morden, Jan Tijs Nijssen, Shannon Bouton, Stefan Knupfer, Surya Ramkumar, Swarna Ramanathan, and Timo Moeller. 2016. An integrated perspective on the future of mobility. McKinsey \& Company, Inc. and Bloomberg New Energy Finance.

11. National Laboratory Connected and Automated Vehicle (CAV) Subgroup. 2014. CAVs Energy Impact.

12. Sarkar, Reuben, and Jacob Ward. 2016. DOE SMART Mobility: Systems and Modeling for Accelerated Research in Transportation. In Road Vehicle Automation 3, eds. G. Meyer and S. Beiker, 137-153. Switzerland: Springer International Publishing.

13. Schreiber, Uschi. 2015. Megatrends 2015: making sense of a world in motion. EYGM Limited.

14. Silberg, Gary, Thomas Mayor, Todd Dubner, Jono Anderson, and Leila Shin. 2015. The clockspeed dilemma, what does it mean for automotive innovation? KPMG LLP.

15. Simon, Karl, Jeff Alson, Lisa Snapp, and Aaron Hula. 2015. Can Transportation Emission Reductions Be Achieved Autonomously? Environmental Science and Technology 49 (24) (November): 13910-13911.

16. Stephens, T.S., J. Gonder, Y. Chen., Z. Lin, C. Liu, and D. Gohlke. 2016. Estimated Bounds and Important Factors for Fuel Use and Consumer Costs of Connected and Automated Vehicles (Technical Report NREL/TP-5400-67216). Golden: National Renewable Energy Laboratory.

17. Tillemann, Levi and Colin McCormick. 2016. Get ready for the world of driverless, electric, shared cars; three disruptive technologies will transform our transportation system. Slate, June, 2016.

18. Townsend, Anthony. 2014. Re-programming Mobility: The digital transformation of 
transportation in the United States. New York: New York University.

19. US Department of Transportation. 2015. Beyond Traffic 2045: Trends and Choices. Washington, DC.

20. US Department of Energy. 2015. Quadrennial Technology Review. Washington, DC.

21. US Department of Transportation. 2016. Federal Automated Vehicles Policy: Accelerating the Next Revolution in Roadway Safety. Washington, DC.

22. Wadud, Zia, Don Mackenzie, and Paul Leiby. 2016. Help or hindrance? The travel, energy and carbon impacts of highly automated vehicles. Transportation Research Part A: Policy and Practice Volume 86 (April). 1-18. Elsevier Ltd.

23. Zimmer, John. 2016. The road ahead: The third transportation revolution; Lyft's vision for the next ten years and beyond. Lyft. https://medium. com/@johnzimmer/the-third-transportation-revolution-27860f05fa91\#.vk6dsybof (Accessed August 30, 2016). 


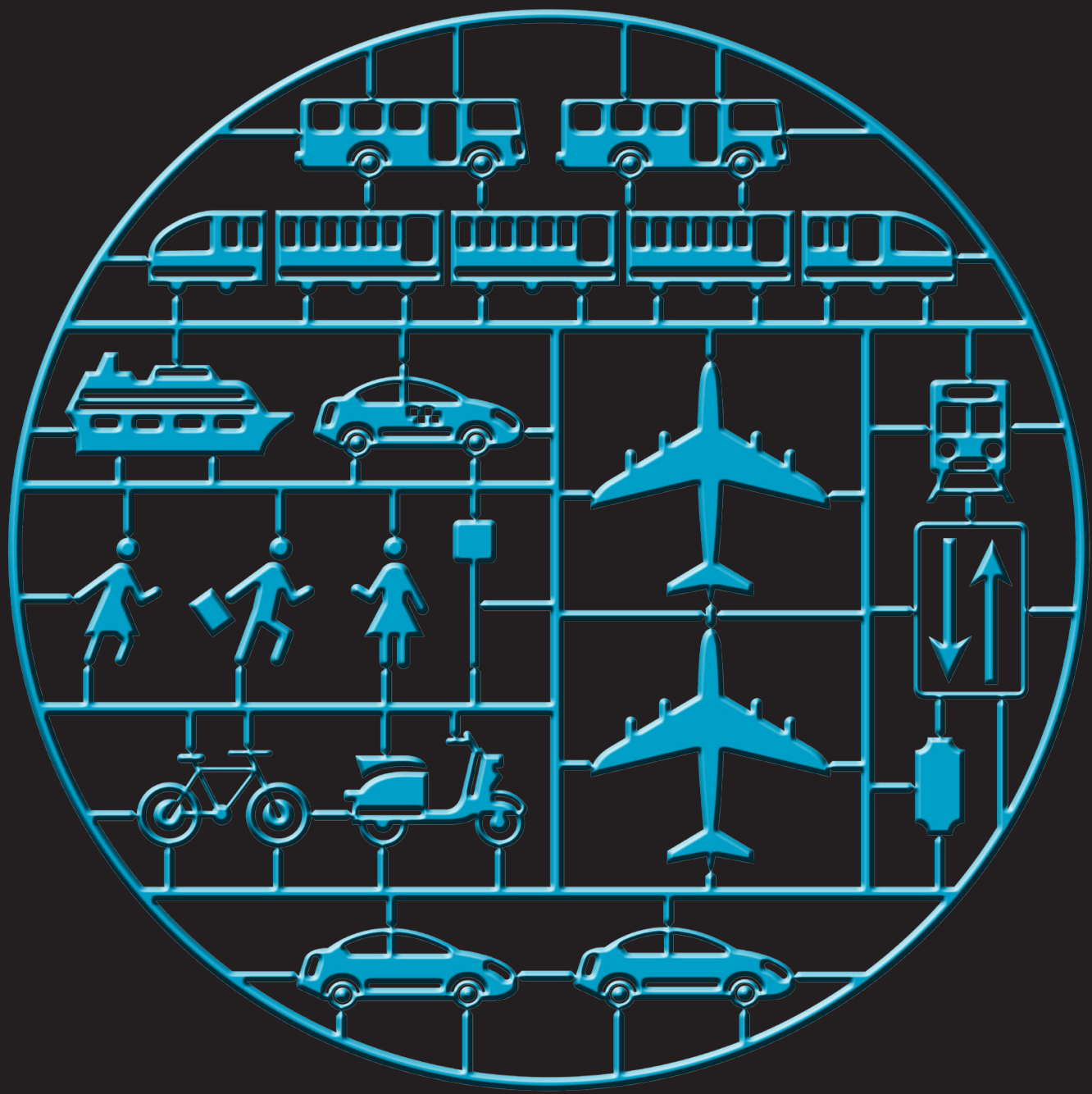

The Transforming Mobility Ecosystem

Enabling an Energy-Efficient Future

\section{DOE/EE-1489}

January 2017

All photos and cover art used under license with iStock (Getty Images)

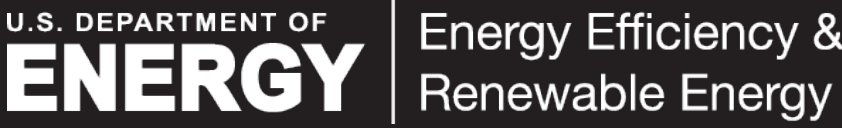

